\title{
Prospection archéologique de la côte nord de Java Centre : le
} district de Batang

Agustijanto Indrajaya, Véronique Degroot

\section{Citer ce document / Cite this document :}

Indrajaya Agustijanto, Degroot Véronique. Prospection archéologique de la côte nord de Java Centre : le district de Batang. In: Bulletin de l'Ecole française d'Extrême-Orient. Tome 99, 2012. pp. 351-383;

doi : https://doi.org/10.3406/befeo.2012.6159

https://www.persee.fr/doc/befeo_0336-1519_2012_num_99_1_6159

Fichier pdf généré le 08/05/2018 


\title{
Prospection archéologique de la côte nord de Java Centre : le district de Batang ${ }^{1}$
}

\author{
Agustijanto IndRAJAYA \& Véronique Degroot ${ }^{2}$
}

\section{Introduction}

Le 13 juin 2013, l'archéologie indonésienne a officiellement fêté ses cent ans d'existence. Si, dès le début du XIX ${ }^{\mathrm{e}}$ siècle, les monuments de Java ont suscité l'intérêt scientifique des Occidentaux ${ }^{3}$, il a fallu attendre le siècle suivant pour que soit fondé le service archéologique des Indes néerlandaises. La tâche de l'Oudheidkundige Dienst était immense. Il s'agissait d'inventorier, étudier et protéger les monuments historiques et les sites archéologiques de l'ensemble de l'Archipel. Des choix durent inévitablement être faits, et c'est sur les temples hindous et bouddhiques du centre et de l'est de l'île de Java que les efforts furent concentrés. Depuis lors, l'archéologie indonésienne s'est considérablement développée. La préhistoire, la période islamique et l'archéologie coloniale occupent désormais des places de choix, tant au sein du Centre national d'archéologie (Pusat Arkeologi Nasional) qu'aux Bureaux de conservation du patrimoine culturel (Balai Pelestarian Cagar Budaya). Malgré ces développements, l'archéologie de la période hindo-bouddhique, et en particulier celle de la période de Java Centre ( $\mathrm{V} I I I^{\mathrm{c}}-\mathrm{X}^{\mathrm{C}}$ siècles), continue d'être une archéologie essentiellement monumentale, davantage tournée vers les régions aux temples vastes et prestigieux (Borobudur, Prambanan), que vers les zones où le patrimoine architectural se fait plus discret.

Pour la période allant du $\mathrm{VIII}^{\mathrm{e}}$ au $\mathrm{x}^{\mathrm{e}}$ siècle, la majorité des temples se trouve dans les plaines de Kedu (district de Magelang, province de Java Centre) et de Yogyakarta. Nul ne saurait contester le fait que la région, qui a également livré nombre d'inscriptions, constitue l'épicentre culturel, et probablement politique, des royaumes hindo-bouddhiques de l'époque. Les vestiges grandioses de Yogyakarta et de Magelang ont quasiment fait oublier que c'est par la côte nord - la seule qui soit propice à la navigation - qu'ont transité les traditions indiennes et les idées nouvelles. Les recherches archéologiques dans les districts septentrionaux se sont jusqu'à présent limitées à quatre inventaires largement incomplets et à la fouille partielle de deux sites (Lebaksiu et Deles). Ici et là, les bureaux locaux du service du tourisme et de la culture ont procédé à des nettoyages de surface et au dégagement de sculptures, mais tout cela s'est fait sans coordination aucune. Des données essentielles telles que le nombre, la distribution et la nature des sites, manquent

1. Les auteurs remercient pour leur soutien le Ministère de la recherche et de la technologie (Kementerian Riset dan Teknologi), le service du tourisme et de la culture du district de Batang, ainsi que le personnel du musée Ronggowarsito (Semarang).

2. Centre national d'archéologie (Pusat Arkeologi Nasional), Jakarta et École française d'Extrême-Orient.

3. On pense, entre autres, à la publication du livre de Sir Thomas Stamford Raffles, The History of Java (1830). 
encore. Aussi l'histoire de la région durant la période hindo-bouddhique est-elle encore floue. Doit-on considérer la côte nord comme la périphérie des royaumes du sud, comme un simple point de transit à l'impact culturel inexistant ou bien comme un carrefour entre les cultures, véritable lieu d'échanges entre Java, le monde malais et le reste de l'Asie ?

\section{Le projet de recherche}

Certes, la côte nord n'a pas jusqu'à présent livré de vestiges comparables à ceux des plaines du sud, mais certains éléments laissent présager que la région a néanmoins un potentiel archéologique important : en effet, les quelque 205 lieux d'intérêt archéologique répertoriés dans l'inventaire de $1914^{4}$, les nombreuses pièces provenant de cette zone et conservées au musée national de Jakarta (Museum Nasional) ${ }^{5}$, la découverte, près de Batang, des plus anciennes inscriptions de Java Centre et enfin la présence, sur le littoral de Java Ouest et dans la région de Rembang, de sites pré-classiques majeurs font penser que la côte nord mérite que l'on s'y arrête.

Le programme de recherche dont nous présentons ici les premiers résultats se propose ainsi d'explorer le potentiel archéologique de la côte nord de Java Centre, afin de mieux comprendre l'étendue et la nature de l'occupation de la région durant la période hindobouddhique. En partenariat avec le Centre national d'archéologie de Jakarta, l'École française d'Extrême-Orient a mis en place un programme de prospection archéologique. Ce projet, débuté en 2012, se déroulera sur plusieurs années et permettra la réalisation d'un inventaire descriptif ainsi que d'une carte archéologique couvrant l'ensemble des districts (kabupaten) situés à l'ouest du mont Muria ${ }^{6}$. Il s'agit de répertorier le plus grand nombre de vestiges : non seulement ceux qui peuvent encore être identifiés par une prospection de surface, mais également ceux qui, aujourd'hui disparus, peuvent être retracés grâce aux sources néerlandaises, aux catalogues des musées et aux archives locales.

La tâche est ardue et souvent ingrate. Les nombreux remaniements des frontières administratives, tant à l'époque coloniale que depuis l'Indépendance, sont autant de sources d'erreur qui rendent difficile, voire impossible, la localisation de certains sites mentionnés dans les documents anciens. Le manque de précision des inventaires existants (absence du nom du village, ou bien de celui du district), ainsi que la large distribution de certains noms de lieux (comme Candi ou Krajan) compliquent encore la tâche. Les transferts successifs de certaines pièces (par exemple, depuis leur site d'origine au bureau du service du tourisme et de la culture, puis à la conservation de Semarang et enfin au musée Ronggowarsito) ont parfois engendré des confusions et les informations concernant leur lieu de découverte n'ont pas toujours été transmises correctement. Enfin, et c'est là

4. Sur les 205 sites répertoriés dans l'inventaire de N. J. Krom (1914), seuls 33 ont livré des pierres de temple ; 60 ont permis de découvrir des sculptures en pierre ; 109 sont des lieux où du petit matériel (bijoux, statuettes en bronze, céramiques, etc.) a été trouvé ; enfin, 3 sites ont livré des inscriptions sur pierre : Tajuk (1447 EC), Ngadoman (1449 EC) et Plumpungan (VIII' siècle).

5. 515 pièces provenant de la côte nord de Java Centre sont conservées au musée national de Jakarta. Il s'agit de sculptures en pierre et en bronze, mais aussi d'objets rituels (lampes, cloches, etc.), de bijoux, de céramiques, de haches polies, etc. 219 objets sont catalogués comme provenant de Semarang; 109 , de Pekalongan ; 154, de Tegal ; 29, de Rembang et 4, de Pemalang. Les provenances exactes sont le plus souvent inconnues. De plus, les divisions administratives mentionnées sont celles de l'époque coloniale et ne correspondent pas, loin s'en faut, aux divisions modernes. Une pièce que le catalogue décrit comme provenant de Semarang peut très bien avoir été découverte dans un village faisant aujourd'hui partie du district de Kendal.

6. Districts de Brebes, Pemalang, Tegal, Pekalongan, Batang, Kendal, ville de Semarang, Semarang et Demak. 
sans nul doute le problème majeur, l'urbanisation croissante de toute la côte a provoqué la disparition de nombreux sites, enfouis sous les constructions modernes ou détruits sans autre forme de procès. Les vols et tentatives de vols d'objets figurant sur la liste du patrimoine - mais placés sous la seule surveillance des villageois -, ainsi que la vente d'antiquités fraîchement déterrées, sont également relativement fréquents et participent à la destruction du patrimoine archéologique de la région ${ }^{7}$. La prospection de surface s'est donc souvent révélée une course contre la montre : documenter le mieux possible ce qui peut encore l'être avant que l'ensemble ne disparaisse. La sensibilisation du grand public apparaît comme un défi majeur pour l'avenir de l'archéologie hindo-bouddhique à Java ${ }^{8}$.

\section{Sites archéologiques du district de Batang : recherches antérieures}

Cette chronique présente les résultats de notre première campagne de prospection, entreprise en avril 2012 dans la région de Batang. L'histoire ancienne du district de Batang est assez peu connue et les publications à ce sujet, très peu nombreuses. Les antiquités de la région font l'objet d'un chapitre dans les inventaires de R. D. M. Verbeek (1891 : 132-134), Krom (1914:136-140), Sri Soejatmi Satari (1977:6-10) et Baskoro Daru Tjahjono (2000:37-40) 9 . Les listes de sites livrées par ces quatre inventaires sont pour le moins disparates. On comprend aisément que l'inventaire le plus ancien soit aussi celui qui répertorie le moins de sites : pour le district de Balang, Verbeek ne référence que Simpar, Deles et Sigemplong; dans l'inventaire publié en 1914, Krom y ajoute onze sites, portant à quatorze le total des sites d'intérêt archéologique de ce district. Parmi ces sites, un seul a véritablement livré des pièces architecturales (Deles), tandis que les autres ont livré des statues (Limpung), des yonis (Panundan, Wanasari) ${ }^{10}$ ou des objets métalliques (Simpar, Tegalsari, Kedondong, Siglagah, Banjar Kidul, Karang Tengah, Wanar, Babadan Ageng et Surjo). C'est avec ces données en main qu'en octobre-novembre 1975, Sri Soejatmi Satari a conduit la première prospection de l'époque post-coloniale sur la côte nord de Java. Elle a alors identifié quatorze sites, dont quatre ont livré des vestiges de construction (Pejaten, Kecepit, Kepyar et Bendosari), trois, des inscriptions (Banjaran, Sojomerto et Indrokilo) et sept, des sculptures en pierre ou des yonis. Si le nombre de sites répertoriés est le même que celui indiqué par Krom (1914), les listes ne se recoupent pas : un seul site (Kecepit/Deles) se retrouve dans les deux inventaires. La raison en est

7. On pense ici aux tentatives de vol des Ganeśa de Silurah et de Pejaten à Batang, à la décapitation d'une sculpture d'Agastya à Sidomukti (Semarang) et à l'enfouissement d'une structure, également à Sidomukti, lors de la construction d’un hôtel à la fin des années 2000.

8. La récente mise en place d'un recrutement de « gardiens » de la culture (pamong budaya) qui seront envoyés dans les diffërentes provinces avec entre autres missions la documentation du patrimoine est un premier pas positif en ce sens.

9. Certains sites répertoriés dans Sri Soejatmi Satari 1977 sont repris dans l'ouvrage que le même auteur a publié l'année suivante, en anglais (Sri Soejatmi Satari 1978). À côté des inventaires, quelques autres publications font mention du patrimoine classique du district de Batang. C'est le cas du livre de Kusnin Asa et al. (2011), publié par le service de la culture et du tourisme du district de Batang (Dinas Kebudayaan dan Pariwisata Kabupaten Batang), du catalogue de la collection de bronzes du musée Ronggowarsito (Hermawanti \& Kussunartini 2000), d'un court article de Sofwan Noerwidi traitant de l'indianisation de la côte nord (Sofwan Noerwidi 2007) et des publications liées aux inscriptions découvertes dans la région (Boechari 1966, republié en 2012 ; Machi Suhadi \& Soekarto 1986 : 3-7 ; Sockarto Artmodjo 1994 : 4-5 : Griffiths 2012).

10. Par yoni, nous entendons ici un piédestal quadrangulaire, muni d'une gouttière d'évacuation des eaux lustrales, faisant saillie et présentant en son centre un profond trou de section carrée, le plus souvent destiné à recevoir un linga. 
simple : Sri Soejatmi Satari a apparemment éliminé de sa liste les sites n'ayant livré que du petit matériel et n'a référencé que ceux où des vestiges étaient encore visibles en 1975 . Quant à l'inventaire de Baskoro Daru Tjahjono, publié en 2000, il ne recense plus que neuf sites, dont trois ayant livré des pierres de temple (Kecepit, Bendosari et Kauman), deux, des inscriptions (Sojomerto, Kepokoh) et quatre, des sculptures en pierre. Une fois encore, les listes ne se recoupent guère, puisque seuls quatre sites (Pejaten, Kecepit, Bendosari et Sojomerto) répertoriés par Sri Soejatmi Satari (1977) se retrouvent dans l'inventaire de Baskoro Daru Tjahjono (2000). Ces disparités ont particulièrement attisé notre curiosité envers l'archéologie du district de Batang. Devait-on y voir le résultat de destructions ayant abouti à la disparition d'une grande partie des sites connus ? Ou bien Sri Soejatmi Satari et Baskoro Daru Tjahjono n'avaient-ils eu ni l'un ni l'autre la possibilité de prospecter le district en profondeur et de vérifier toutes les informations disponibles, y compris les sources néerlandaises?

\section{Le district de Batang : géographie}

Avant de présenter l'inventaire des sites archéologiques, il convient de décrire brièvement la région (fig. 1). Le district de Batang se situe sur la côte nord de Java, dans la province de Java Centre. Il est bordé par le district de Pekalongan (à l'ouest), par le district de Kendal (à l'est) ainsi que par les districts de Banjarnegara et Wonosobo (au sud). Le territoire de Batang est divisé en seize sous-districts offrant des paysages très contrastés ". Bordées par la mer au nord, les terres s'élèvent rapidement vers le sud, où la limite du district correspond à la ligne de crête de la chaîne des Serayu du Nord, culminant à plus de $2500 \mathrm{~m}$ d'altitude.

La plaine côtière, généralement étroite et profonde de quelques kilomètres tout au plus, ne s'élargit que dans les régions de Tulis et de Batang (à l'ouest), ainsi que dans la partie orientale du sous-district de Gringsing (à l'est). Dans les autres régions, une chaîne de collines sèches culminant à une altitude de $350 \mathrm{~m}$ court parallèlement à la côte. Au sud de la plaine côtière et des collines, le relief est modelé par les massifs volcaniques qui dominent le centre de Java. Les vallées et les collines alternent, suivant l'orientation sudnord dictée par la présence des monts Prahu, Kemulan et Kendalisodo. Dans les parties hautes du massif montagneux, les vallées sont étroites et leurs pentes, escarpées. Dans les parties basses (en dessous de $800 \mathrm{~m}$ d'altitude), elles s'ouvrent et s'élargissent par endroits, formant ainsi de petites plaines, comme autour des villes de Limpung, Tersono, Blado et Bawang, ou dans la région de Sojomerto.

Le district est parcouru de centaines de petites rivières, coulant du sud au nord, et de quatre rivières plus importantes (Kupang, Lojahan, Boyo et Kuto) qui prennent leur source près des sommets des volcans de la chaîne des Serayu. La rivière Kupang, qui naît sur les hautes pentes des monts Kendal et se jette dans la mer à Pekalongan, constitue, sur une grande partie de son cours, la frontière entre les districts de Batang et de Pekalongan. La rivière Boyo, dont l'estuaire se trouve dans le sous-district de Tulis, se divise quant à elle en deux en amont : la Kitiran, qui prend sa source près du mont Butak, d'une part, et la Tinap, issue du mont Kemulan, d'autre part. Enfin, le plus important réseau hydrographique de la région est sans nul doute celui que constituent la rivière Kuto et ses trois principaux affluents, la Petung, issue du mont Kemulan, l'Arus, provenant de la région du mont Ngaglik, et la Belo, qui descend du mont Prahu. Les trois rivières suivent un

11. Il s'agit des kecamatan de Bandar, Banyuputih, Batang, Bawang, Blado, Gringsing, Kandeman, Limpung, Pecalungan, Reban, Subah, Tersono, Tulis, Warungasem, Wonotunggal. 
cours orienté sud-nord jusqu'à leur confluence, dans le district de Tersono. Là, le cours de la rivière née de leur rencontre oblique vers l'est, en longeant la chaîne de collines est-ouest qui sépare les contreforts des Serayu de la côte. La rivière reprend ensuite une orientation sud-nord avant de se jeter dans la mer près du village de Gempolsewu, dans le district de Kendal.

L'agriculture s'est adaptée à la diversité des paysages. Dans les plaines alluviales de Batang et de Gringsing s'étendent des champs de riz irrigués, tandis que la chaîne de collines bordant la côte est recouverte de plantations d'arbres (teck et hévéa surtout) et de cultures non irriguées. Au sud de cette zone, le paysage agricole est très morcelé. Les collines y sont également occupées par une végétation arborée (melinjo, sengon, etc.) et par des cultures maraîchères, alors que les vallées et les zones au relief moins marqué sont dédiées à la culture du riz. Les rizières y sont souvent irriguées, mais on y trouve aussi des rizières pluviales, surtout dans la partie orientale du district. Au-dessus de 700$800 \mathrm{~m}$ d'altitude, les rizières disparaissent pour laisser place à une végétation arborée et à des champs non irrigués, puis aux forêts (au-delà de $1200-1300 \mathrm{~m}$ ).

\section{Inventaire des sites archéologiques du district de Batang}

L'inventaire des sites archéologiques du district de Batang a pu être réalisé au cours de la campagne de prospection qui s'est déroulée en avril 2012. Une liste des sites, accompagnée de leur localisation administrative et de leurs coordonnées géographiques, ainsi que d'une brève description, est donnée en annexe de cette chronique ${ }^{12}$.

Les sites identifiés sont au nombre de quarante-deux. Parmi ceux-ci, neuf n'ont été identifiés que par l'intermédiaire de sources secondaires et ne semblent pas avoir laissé de vestiges visibles en surface ${ }^{13}$. Le site de Kebonbatur, par exemple, ne nous est connu que grâce à une note figurant dans les archives du service du tourisme et de la culture du district de Batang, lequel nous apprend qu'un petit yoni y était encore visible en 1984-1985 (Data Peninggalan Batang 1985). De même, sur le site de Penundan, où notre prospection d'avril 2012 n'a donné aucun résultat, avaient pourtant été trouvés, en 1903 (Notulen 1903a : 103 ; 1903b : XC ; Sell 1912 : 170 ; Krom 1914 : no 418, photo OD 5572), deux petits yonis, aujourd'hui conservés au musée national de Jakarta (MNI 363b/4547 et MNI 363c/4548).

Sur trois sites seulement (Sigit, Batur et Punden Wali Ajar Pendek), nous avons pu observer la présence d'une structure encore en place. À Sigit (Pecalungan, Pecalungan), dans une zone de collines peu accentuées entre les vallées de Limpung et Bawang, on peut voir un petit tertre de pierres et de terre d'environ $5 \mathrm{~m}$ de côté et $80 \mathrm{~cm}$ de haut (fig. 2), sur lequel nous avons trouvé les fragments d'une statue de taureau (fig. 3). Un peu plus loin, devant une maison du village de Siguci, se trouve un Gaṇeśa fortement abîmé qui, selon les habitants du lieu, proviendrait de Sigit (fig. 4). Le site de Batur (Silurah, Wonotunggal), établi dans les contreforts du mont Kendalisodo, est ce que l'on appelle un

12. Les divisions administratives mentionnées ici sont celles qui étaient en usage lors de la campagne d'avril 2012. Les coordonnées géographiques ont été relevées selon le système de référencement WGS 84, à l'aide d'un GPS portable. Les conditions n'étant pas toujours optimales, une marge d'erreur de l'ordre de $15 \mathrm{~m}$ est possible, notamment pour les sites de montagne ou pour ceux situés dans des zones où la couverture végétale est dense.

13. Kanyaran et Kebonbatur dans le sous-district de Bandar, Penundan et Kedongdong dans le sousdistrict de Banyuputih, Klawen, Banaran et Purbo dans le sous-district de Bawang, Indrokilo dans le sous-district de Pecalungan, ainsi que Banjaran dans le sous-district de Reban. 
punden, une structure formée de terrasses de terre superposées (trois dans le cas de Batur) et renforcées par des murs de soutènement en pierres de rivière. Dans l'angle nord-est de la deuxième terrasse, se trouvent un yoni (fig. 5), quelques pierres de taille présentant un profil, ainsi qu'un petit Gaṇeśa très abîmé et sans tête (fig. 6). Quant au Punden Wali Ajar Pendek, situé dans le village même de Batur, il s'agit également d'une structure en terrasses construite en pierres de rivière, mais celle-ci n'a pas livré de vestiges clairement attribuables à la période hindo-bouddhique (fig. 7).

Hormis ces trois structures encore en place et visibles en surface, neuf autres sites ont livré un matériel suggérant la présence ancienne d'un bâtiment : des sculptures, mais surtout des pierres de taille et des fragments de décor architectural. C'est le cas des sites de Cepit, Kepyar, Deles, et Klenteng dans le sous-district de Bawang (fig. 8-15), Balekambang dans le sous-district de Gringsing, Sidomulyo dans le sous-district de Reban, Pejaten et Kauman dans le sous-district de Tersono, ainsi que de Watu Gajah (Kupang) dans le sous-district de Wonotunggal. Tous ces sites ont livré des sculptures permettant de les identifier comme des lieux de culte hindous, à l'exception de Kepyar, qui n'a révélé aucune sculpture, et de Balekambang, d'où provient une statue identifiée tantôt comme Śrī, tantôt comme Vasudhārā.

Sur la plupart des autres sites ont été trouvés des sculptures et/ou des yonis. Quatre d'entre eux n'ont livré que du petit matériel (bronzes, céramiques). Notons encore que sept sites ont quant à eux fourni des inscriptions : Wutit (Bandar), Deles (Bawang), Kepokoh (Blado), Balekambang (Gringsing), Indrokilo (Pecalungan), Sojomerto (Reban) et Banjaran (Reban).

Avant d'aller plus loin dans l'interprétation historique, il convient de dresser ici une description plus détaillée des principaux sites du district de Batang. Nous nous intéresserons donc aux sites de Balekambang, Pejaten, Klenteng, Cepit, Kepyar, Klawen et Deles.

\section{Balekambang}

Le site de Balekambang se situe à environ $1 \mathrm{~km}$ de la mer, sur le versant est d'une colline qui forme l'extrémité orientale de la chaîne bordant la côte de Gringsing à Tulis. La colline, qui culmine à une cinquantaine de mètres, est recouverte d'arbres et a été partiellement transformée en une plantation d'hévéas, propriété de la Société forestière de Sawangan (PT Perkebunan Sawangan). À son pied, au lieu-dit Balekambang, se trouve une source au débit assez important, qui donne naissance à une petite rivière, la kali Buangan. À environ $600 \mathrm{~m}$ à l'est du site, coule la rivière Anyar/Segan, dans l'estuaire de laquelle mouillent encore les bateaux de pêche. Des rizières irriguées s'étendent à l'est de Balekambang, jusqu'à la rivière Anyar et même au-delà.

Le site de Balekambang se compose de trois parties : l'une d'elles se trouve directement sur le flanc de la colline; une autre est au pied de celle-ci et la dernière se trouve dans la plaine alluviale. La partie établie sur la colline a été partiellement détruite par un récent glissement de terrain et on n'y distingue plus guère de vestiges. C'est pourtant de cette zone que proviendrait l'inscription de Balekambang. La pierre, qui mesurait à l'origine $85 \times 44 \times 34 \mathrm{~cm}$, a été brisée en deux ; elle est maintenant conservée au musée Ronggowarsito (04.00076 et 04.00078 ), à Semarang. On peut y voir cinq lignes d'un texte en écriture dite pallava et en langue sanskrite. Soekarto Kartoatmodjo l'a datée des environs de l'an 600 de notre ère et y a lu une possible référence à la rivière Yamuna (Goenadi Nitihaminoto et al. 1978 : 19). L'inscription de Balekambang a été étudiée plus récemment par Arlo Griffiths (2012: 474-477) qui, sur la base d'une comparaison paléographique avec l'inscription de Canggal, la situerait dans la seconde partie du 
$\mathrm{VII}^{\mathfrak{e}}$ siècle. Le même auteur en propose une transcription et une traduction, que nous reprenons ici : "May this life (on earth) be long for this man the strength of whose arms is unsurpassed, who has revealed the crystal-clear water, [...] by name! $»$.

À une centaine de mètres de là, au pied de la colline, près d'une source aujourd'hui recouverte en partie par une structure en béton (fig. 16), d'autres vestiges ont été découverts. Sur place, on peut encore voir une sculpture de nāga (dont la tête a été remodelée avec du ciment ; fig. 17) ainsi que de nombreuses pierres de temple, partiellement réutilisées dans la construction d'un bain moderne (fig. 18). Sri Soejatmi Satari (1977) avait encore pu observer à cet endroit deux statues d'oie (désormais conservées au musée Ronggowarsito, 04.00254 et 04.00255 ) et un makara tenant un oiseau dans sa gueule $(04.00266$; fig. 19). Ce type de makara est l'un des plus fréquents dans l'art de Java Centre. La symétrie de la trompe, le collier en pétales de lotus et le motif végétal sculpté derrière la tête permettent d'associer le makara de Balekambang à ceux de Loro Jonggrang ; on pourrait donc lui attribuer une date post quem qui se situerait aux alentours du milieu du $1 x^{\mathrm{e}}$ siècle.

En plus de ces pièces, la prospection de 1978 (Goenadi Nitihaminoto et al. 1978) a relevé la présence d'une sculpture de déesse en position assise, qui a été identifiée comme étant une représentation de Śrī Vasudhāra. La statue, aujourd'hui conservée au musée Ronggowarsito (04.00492 ; fig. 20), est fortement endommagée et la restauration au ciment dont elle a été l'objet ne lui rend pas hommage, mais on peut encore en discerner les principales caractéristiques. La déesse est représentée assise en tailleur sur un lotus, une auréole derrière la tête. Elle a quatre bras. Dans la main supérieure droite, elle tient un rosaire ; dans la main supérieure gauche, un épi de riz. Sa main inférieure droite est en varada-mudrā, tandis que sa main inférieure gauche est posée sur son giron, un lotus sur la paume. La déesse porte une riche parure, incluant un diadème, de lourdes boucles d'oreilles, un collier, une double bande de perles sur le buste et des bracelets. La présence de trois bracelets sur chaque bras et la façon dont les pans de tissus tombent sur le devant du trône rappellent l'art de Plaosan ou de Loro Jonggrang, ce qui permet de placer la sculpture dans le courant du $\mathrm{Ix}^{\mathrm{e}}$ siècle ${ }^{14}$.

Selon l'inventaire du musée Ronggowarsito, six autres pièces proviendraient également de Balekambang : une statue de Durgā (04.00077), un deuxième makara (04.00079), deux jaladvāra (04.00080 et 04.00081) $)^{15}$ et deux antéfixes $(04.00082,04.00083)$. La Durgā est brisée en trois et malheureusement tellement érodée qu'il est impossible d'en définir le style. La déesse est représentée debout sur le buffle. Elle a huit bras et l'on peut encore distinguer la conque, dans sa main supérieure gauche, ainsi que le disque, dans sa main supérieure droite. La deuxième main supérieure droite tenait sans doute une épée courte ou une massue. Le reste des attributs n'est pas identifiable. Le second makara attribué au site de Balekambang dans cet inventaire (fig. 21) ne forme pas une paire avec celui que nous avons mentionné plus haut. Selon toute vraisemblance, il s'agit là aussi d'un makara d'échiffre, mais il devait faire partie d'un escalier de plus petites dimensions, car les deux tiers inférieurs de la face intérieure ne sont pas décorés. Ici, la trompe est clairement symétrique et enroulée. Le collier est entièrement végétal et, dans la gueule du monstre, on peut voir une tête de lion. On retrouve derrière la tête du makara un motif

14. L'ensemble n'est pas sans rappeler le relief représentant Śrī Lakșmī entre deux éléphants du candi Nogosari, conscrvé au musée Sono Budoyo de Yogyakarta ( $\left.\mathrm{n}^{\circ} 1304\right)$. Voir, par exemple, Fontein $1990: 142-143$.

15. Le terme jaladiāra désigne ici un conduit taillé dans un seul bloc de pierre, généralement terminé par une gargouille. 
assez similaire à celui que l'on trouve sur le premier exemplaire, ce qui laisse penser que les deux sculptures remontent plus ou moins à la même époque ( $\mathrm{IX}^{\mathrm{C}}$ siècle). Des deux jaladvāra, l'un est un simple conduit sans aucun décor (04.00080), alors que l'autre est d'un type assez singulier (04.00081) : l'extrémité du conduit a la forme d'un crocodile, gueule ouverte et tous crocs visibles; une jeune femme se tient à cheval sur l'animal, les jambes repliées, le buste penché en avant et les mains posées sur la tête de la bête ; ses cheveux bouclés lui tombent le long du dos jusqu'aux pieds. Le tout est malheureusement taillé dans un conglomérat grossier, si bien qu'aucun détail n'est visible ${ }^{16}$.

$\grave{A}$ environ $200 \mathrm{~m}$ de la source, en direction du nord-est, une rapide prospection de surface a permis de mettre au jour de nombreux tessons, parmi lesquels une majorité de céramiques tardives d'origine chinoise et thaï, datant de la fin du $x v^{\mathrm{e}}$ ou du début du $\mathrm{XVI}^{\mathrm{e}}{ }^{17}$ siècle.

Il ressort de ces informations que le site de Balekambang a au moins été occupé du $V_{I I}{ }^{\mathrm{e}}$ siècle au IX $X^{\mathrm{e}}$ siècle. Dans le courant du IX $X^{\mathrm{e}}$ siècle, plusieurs structures religieuses en pierre y furent construites, incluant sans doute un bain et un temple. Le site a également connu une occupation tardive vers la fin du $x^{e}$, mais il n'y a pas, jusqu'à présent, de témoin matériel étayant l'hypothèse d'une occupation continue.

\section{Pejaten}

Plus à l'intérieur des terres, dans la vallée de Tersono, environ $300 \mathrm{~m}$ à l'est de la rivière Arus, se trouve le site de Pejaten. L'endroit est aujourd'hui au milieu d'une rizière. Le matériel archéologique a été découvert dispersé sur une assez grande surface. Quelques briques de grand format sont encore visibles dans les rizières, mais les pièces ont, pour la plupart, été déplacées. On peut voir rassemblés, au centre du village de Pejaten, un Gaṇeśa, un taureau, une pierre gravée, quelques fragments de briques et un grand mortier de pierre. Le linteau et le seuil de porte signalés par Goenadi Nitihaminoto et al. (1978: 23) semblent avoir disparu.

Selon les villageois, une urne en pierre contenant une bague et des boucles d'oreilles aurait été découverte dans les champs non loin de là. En 1975, Sri Soejatmi Satari (1977: 7-8, photos 11-13) avait noté la présence de quatre taureaux supplémentaires, d'un Viṣnu, d'un deuxième Gaṇeśa et de deux grands éléments de porte en pierre, ainsi que de divers fragments architecturaux. Elle avait également fait part de la découverte, sur les terres du même desa, mais dans le hameau de Rejosari, de deux statues de taureau et d'une pièce de couronnement (Sri Soejatmi Satari 1977: 8, photo 14). Certaines de ces pièces se trouvent aujourd'hui au musée Ronggowarsito. C'est le cas de la statue de Viṣnu (MR 04.00067) ainsi que de deux Gaṇeśa (MR 04.00013 [fig. 25] et 0.00014) ${ }^{18}$. L'inventaire du musée mentionne trois autres pièces en indiquant qu'elles proviennent de Rejosari, mais sans autre précision sur leur origine exacte : il s'agit de deux taureaux (MR 04.00090;04.00091) et d'un Gaṇeśa (MR 04.00089).

16. Nous n'avons pas connaissance d'une pièce qui soit similaire à ce jaladvāra: Sell (1912:160) donne la description d'une pièce identique provenant de Rogoselo (district de Pekalongan). Ce jaladvāra, qui mesure pourtant près de $1 \mathrm{~m}$ de long, n'avait pas été remarqué par les précédents visiteurs. Il y a donc de bonnes raisons de croire qu'il s'agit d'une erreur dans le catalogue du musée Ronggowarsito : la pièce numérotée 04.00081 proviendrait de Pekalongan, non de Batang.

17. Nous remercions $M^{\text {me }}$ Marie-France Dupoizat, qui a bien voulu faire l'expertise d'un échantillon de ces céramiques à partir de photographies.

18. Hormis celui qui se trouve encore sur le site, Sri Soejatmi Satari ne mentionnait qu'un seul autre Gaṇeśa. 
Le piètre état de conservation de la plupart des pièces ne permet guère d'en préciser le style et la date. Toutefois, trois sculptures se distinguent par leur iconographie quelque peu inhabituelle : le Ganeśa encore sur place à Pejaten, le Gaṇeśa n ${ }^{\circ} 04.00089$ du musée Ronggowarsito et la statue $n^{\circ} 04.00067$, identifiée comme un Viṣnu par Sri Soejatmi Satari (1977:10;1978:4).

Le Ganeśa qui se trouve sur le site est une sculpture sur stèle de près de $1 \mathrm{~m}$ de haut (fig. 22) ${ }^{19}$. La statue a des proportions massives; ses épaules sont larges et carrées, son ventre, proéminent et sa trompe, épaisse, à l'inverse de ses jambes, qui semblent presque frêles. La divinité est représentée assise, une jambe repliée sous le ventre et l'autre, légèrement pendante. Les bras sont au nombre de quatre, mais toutes les mains sont abîmées, si bien qu'il est impossible d'en distinguer la position ou les attributs. Le dieu porte des bracelets aux bras et aux poignets, ainsi qu'un collier et une ceinture autour du ventre. Plusieurs éléments rendent cette sculpture atypique par rapport à la production habituelle de Java Centre. De fait, sa position diffère de ce que l'on pourrait appeler le canon javanais, où le dieu à tête d'éléphant est presque toujours représenté assis en tailleur, avec les plantes des pieds qui se touchent. À notre connaissance, les seules représentations javanaises où l'on voit le dieu en lalitāsana ou dans une position approchante sont, d'une part, les bronzes d'influence indienne de la fin du $\mathrm{VIII}^{\mathrm{e}}$ ou du début du IX ${ }^{\mathrm{e}}$ siècle et, d'autre part, certaines statues plus tardives relevant du tantrisme et généralement associées à la période de Singhasāri-Majapahit (XIII ${ }^{\mathrm{e}} \mathrm{XIV}^{\mathrm{e}}$ siècles) ${ }^{20}$. En sus, il faut mentionner le Ganeśa de la jalan Mayor Ruslan, à Palembang, dont la datation, après avoir été placée au XII ${ }^{\mathrm{e}}$ siècle (McKinnon $1985: 18$ ), a finalement été fixée au VII ${ }^{\mathrm{e}}$-VIII ${ }^{\mathrm{e}}$ siècle (Brown 1987). Dans ses proportions comme dans sa position, l'exemplaire de Pejaten se rapproche davantage des sculptures anciennes que des statues de Java Est. Le traitement des pieds est également comparable à celui de ces sculptures du VIII' siècle : ils sont en effet de longueur humaine (et non courts comme ceux des Ganeśa de Singhasāri) et le pied gauche est figuré plante vers le haut. Le liseré perlé qui borde la stèle rappelle également les bronzes du vill ${ }^{\mathfrak{C}}$ ou du début du IX $\mathrm{X}^{\mathfrak{c}}$ siècle trouvés à Java Centre. En revanche, l'absence de jatămukuta est assez singulière, puisqu'à notre connaissance, toutes les autres statues de Ganeśa de Java le représentent couronné du chignon des ascètes. Les seules images trouvées en Indonésie auxquelles on puisse comparer le Ganeśa de Pejaten sont donc de manufacture ou d'influence indienne et s'avèrent, pour la plupart, relativement anciennes. L'absence de chignon pointe encore dans la direction de l'Inde, où cette tradition existe dès le $\mathrm{VI}^{\mathrm{e}}-\mathrm{VII}^{\mathrm{e}}$ siècle.

Le Ganeśa $n^{\circ} 04.00089$ du musée Ronggowarsito est stylistiquement si proche du Gaṇeśa de Pejaten qu'il n'y a guère de doute sur le fait que les deux sculptures proviennent du même site. On retrouve les proportions massives, le ventre rond et proéminent, souligné par la même corde, et les bras courts (fig. 23). Les pieds sont également dans une position atypique, mais différente de celle de notre premier Ganeśa. Le Ganeśa du musée Ronggowarsito est en effet assis en tailleur, comme la plupart des Ganeśa javanais ; toutefois, ses plantes de pieds ne se touchent pas comme à l'accoutumée : le pied gauche

19. Selon Goenadi Nitihaminoto et al. (1978:22), cette statue de Ganeśa a été découverte en 1974.

20. Pour donner un exemple de Ganeśa en bronze dans une position similaire, on peut citer la petite statue n" OM 4-1940, 1940, conservée au musée municipal de La Haye (Haags Gemeentemuseum) et reproduite par Lunsingh Scheurleer \& Klokke (1988:68). À titre d'exemples plus tardit's, on peut penser au Gaṇeśa de Singosari conservé au musée national d'ethnologie (Rijksmuseum voor Volkenkunde) de Leiden (RMV 1403-1681), répertorié entre autres par Edi Sedyawati (1994:336), ou à celui du bureau de conservation du patrimoine culturel (Balai Pelestarian Cagar Budava) de Yogyakarta (BG 558). 
est ici placé sur le pied droit, une position qu'on ne retrouve, à notre connaissance, sur aucun autre Ganeśa javanais.

La statue $\mathrm{n}^{\circ}$ 04.00067, conservée au musée Ronggowarsito de Semarang, mais provenant de Pejaten, constitue de loin l'image la plus atypique découverte sur le site. Il s'agit d'une stèle ovale ornée d'un haut-relief très érodé représentant une divinité masculine à quatre bras, flanquée de deux acolytes (fig. 24). Le dieu est figuré debout, coiffé d'une mitre cylindrique, ce qui a conduit Sri Soejatmi Satari $(1977: 10 ; 1978: 4)$ et, à sa suite, Nadine Dalsheimer et Pierre-Yves Manguin (1998:104), à rapprocher cette sculpture du Vișṇu $\mathrm{n}^{\circ} 1$ de Cibuaya et à l'inscrire dans la grande famille des Vișnu mitrés, datée des $\mathrm{V}^{\mathrm{e}}-\mathrm{Vl}^{\mathrm{e}}$ siècles, que l'on retrouve sur de nombreux sites côtiers de l'Asie du Sud-Est méridionale. Cette identification et ces liens stylistiques ne tombent cependant pas sous le sens lorsqu'on observe la statue de près ${ }^{21}$. D'un point de vue iconographique, seuls deux des quatre attributs sont clairement identifiables et correspondent à des attributs de Vișnu : la conque (dans la main supérieure gauche) et la massue (dans la main inférieure gauche). L'objet tenu dans la main supérieure droite et identifié par Sri Soejatmi Satari comme étant un disque pourrait en fait être un rosaire. En effet, le disque est généralement tenu entre deux doigts ; sur la statue du musée Ronggowarsito, au contraire, on voit clairement que la main se referme en passant au travers de l'objet, ce qui correspond à la façon de tenir un rosaire. Le quatrième attribut, celui que le dieu tient dans la main inférieure droite, n'avait pu être identifié par Sri Soejatmi Satari. À y regarder de près, il nous semble cependant deviner une forme proche du kendi, qui serait ici tenu à l'horizontale. On peut effectivement distinguer une panse bulbeuse, un col étroit et un bec pointant vers le haut ${ }^{22}$. Quant aux acolytes placés aux pieds du dieu, il est difficile de suivre la proposition de Sri Soejatmi Satari, qui suggérait d'y reconnaître Śrī et Lakṣmī. Si le personnage à la gauche du dieu présente clairement un profil humain, le personnage à sa droite, avec sa large tête triangulaire, ressemble davantage à un animal. En lieu et place d'un Vișnu, nous pourrions très bien avoir affaire à un Hari-Hara détenant, d'un côté, les attributs de Vișnu (massue, conque et peut-être Garuda personnifié) et de l'autre, ceux de Śiva (rosaire, kendi et taureau) ${ }^{23}$. Cette nouvelle identification semblerait confirmée par la présence, à Pejaten, d'une pierre sculptée où l'on peut voir le triśüla de Śiva surmonté du cakra de Vișnu. D'un point de vue iconographique, la statue de Pejaten est très similaire à une image sur feuille d'or conservée au musée national de Jakarta (MNI 4567) et provenant du village de Gemuruh, dans le district de Wonosobo (Brandes 1904). Hari-Hara y est représenté debout, flanqué du taureau (à sa droite) et de Garuḍa (à sa gauche). Comme dans le cas de la statue de Pejaten, les attributs choisis pour illustrer la moitié śivaïte du dieu sont le rosaire (placé dans la main supérieure droite) et le kendi (dans la main inférieure droite). Plusieurs autres pièces d'or ont été découvertes à Gemuruh en même temps que le Hari-Hara. L'une d'entre elles, figurant Śiva, porte une inscription datée paléographiquement du début du vIII" siècle (Damais 1968: 439). D'un point de vue stylistique, la grosse tête de la statue, ses proportions maladroites et

21. Ce que ni Sri Soejatmi Satari ni N. Dalsheimer et P.-Y. Manguin n'avaient pu faire. Lorsque Sri Soejatmi Satari avait vu la sculpture, elle était encore partiellement enterrée. Quant à N. Dalsheimer et P.-Y. Manguin, ils n’avaient pas eu l'occasion de voir la statue et avaient dû se contenter de la description publice en 1978 par Sri Socjatmi Satari.

22. Nous remercions notre colliegue Arlo Griffiths d’avoir attiré notre attention sur ce point.

23. Le relief aux trois quarts érodé qui se trouve entre la tête et la main supéricure gauche du dieu pourrait être l'ébauche d'un trident. 
le pli central de son pagne rapprochent la pièce du musée Ronggowarsito du Vișṇu $\mathrm{n}^{\circ} 1$ de Cibuaya ; toutefois, la sculpture est tellement érodée qu'il est difficile de tirer des conclusions définitives de ces similitudes. Nous ne pouvons cependant nous empêcher de noter que l'identification de la sculpture du musée Ronggowarsito comme un HariHara, divinité rarement représentée à Java, tend à la rapprocher des statues relativement nombreuses de ce dieu qui ont été trouvées dans le sud et le centre du Cambodge et qui sont généralement datées des $\mathrm{VII}^{\mathrm{e}}-\mathrm{VIII}{ }^{\mathrm{C}}$ siècles.

\section{Klenteng (Sibebek)}

À 7,5 km en amont de Pejaten, dans la vallée de Bawang, se trouve le site de Klenteng. L'endroit est situé à une altitude d'environ $700 \mathrm{~m}$, dans les contreforts du mont Prahu. C'est aujourd'hui une rizière. À près de $200 \mathrm{~m}$ à l'est, coule la rivière Tok Dandang/ Kambangan, un affluent de la rivière Arus.

Le long de la route, sous un appentis, on peut voir une statue représentant le taureau de Śiva (fig. 13), un yoni et deux pierres cylindriques décorées de rangs de pétales de lotus. Selon notre informateur, les objets ont été trouvés près de la rivière avant d'être transportés jusqu'à leur emplacement actuel.

Goenadi Nitihaminoto et al. (1978: 15-17) notent, en plus des objets précités, la présence d'une jarre à quatre oreilles, d'une sculpture de « Śiva Mahāguru » (Agastya), d'une autre de Nandīśvara et d'un deuxième yoni. La statue d'Agastya se trouve aujourd'hui au musée Ronggowarsito (04.00257).

L'inventaire du musée Ronggowarsito répertorie en outre une Durgā qui proviendrait également de Klenteng (04.00263 ; fig. 15). La déesse est représentée avec six bras, debout sur le corps du buffle. Son bras supérieur droit est levé, comme prêt à lancer le cakra qu'elle tient dans sa main. La main droite médiane tient une épée et la main droite inférieure, une corde, nouée autour de la queue du buffle. Quant à la main supérieure gauche, elle tient une conque et la main gauche médiane, un objet cylindrique (peut-être une massue). Sa main inférieure gauche est placée sur la tête du démon, lequel émerge d'une blessure au cou du buffle. Le démon, représenté sous les traits d'un nain, joint ses mains en añjali-mudrā. Il faut aussi souligner que la statue présente de nombreux détails inhabituels. Tout d'abord, il s'agit d'une des rares Durgā à six bras trouvées à Java (les Durgā à huit bras étant de loin les plus fréquentes) ${ }^{24}$. De plus, la massue et la corde ne figurent pas parmi les attributs usuels des Durgā javanaises. La corde, ou plus précisément le nœud coulissant, apparaît au moins sur un autre exemplaire de Durgā, trouvé à Semarang et conservé aujourd'hui au musée national (MNI 127a). Toutefois, la façon dont la corde est figurée ici, enroulée autour de la queue du buffle, ne se retrouve, à notre connaissance, que sur un seul autre exemplaire, provenant du plateau de Dieng (photo OD 11294). La main inférieure gauche, gentiment posée sur la tête de l'asura, constitue également un détail inhabituel pour les sculptures de Java Centre. En effet, cet élément iconographique est essentiellement associé aux statues de l'époque de Singhāsari, comme les Durgã du candi Jago et de Singosari. Le long vêtement de la Durgā de Klenteng rappelle ainsi, dans sa structure, celui de la Durgā de Loro Jonggrang, tandis que les proportions allongées de la statue font écho aux Durgā de Sambisari ou de candi Suko, un temple aujourd'hui disparu, près de Boyolali. Il est donc probable que la Durgā de Klenteng soit postérieure à la seconde moitié du $\mathrm{IX}^{\mathrm{c}}$ siècle.

24. On peut admirer une autre Durgā à six bras au candi Merak (Klaten). 
Enfin, la présence d'un yoni, d'un dvārapāla ainsi que de deux des dieux de l'habituelle triade javanaise (Durgā, Agastya, le troisième étant Gaṇeśa) suggère qu'un temple se dressait autrefois sur le site de Klenteng.

\section{Cepit}

Plus en amont encore, sur la crête d'une colline culminant à $980 \mathrm{~m}$ d'altitude, le site de Cepit surplombe la vallée de Bawang. La colline est longée par la rivière Arus (à l'ouest) et par la rivière Belo (à l'est).

Sur place, au milieu d'une plantation d'arbres et près d'une tombe musulmane, il ne reste aujourd'hui que trois pierres de taille : une grande pierre rectangulaire de $143 \times$ $57 \times 23 \mathrm{~cm}$, une pierre plus petite de $46 \times 26 \times 17 \mathrm{~cm}$ ainsi que la partie inférieure d'un yoni mesurant $67 \times 69 \times 43 \mathrm{~cm}$ (fig. 8 ). Ce dernier présente une modénature particulière, avec une succession de trois triples bandeaux ${ }^{25}$.

Les données plus anciennes permettent toutefois de conclure qu'un temple se dressait autrefois sur la colline de Cepit. La première description du site nous est fournie par G. A. Pet, un ingénieur de la Residentie de Bagelen (Notulen 1868 : 23). Celui-ci note la présence, " en un lieu nommé Selo Kasoer, près du village de Delles ", d'une statue masculine en position accroupie, d'une sculpture représentant une vache, d'une sorte de jarre, d'une pierre décorée, d'une cuve à eau (watervat) et de « quelques autres objets indescriptibles ». Ces informations sont reprises par Verbeek (1891) et complétées par Sell en 1912. Ce dernier, qui nous donne en passant le nom du hameau (Lembu) où se trouvent les vestiges, fournit une description assez précise des sculptures (Sell 1912 : 173174). Il identifie entre autres un Gaṇeśa (de $76 \mathrm{~cm}$ de haut), une statue du taureau de Śiva $(105 \times 35 \times 65 \mathrm{~cm})$, trois lingas, deux colonnettes (zuiltjes) décorées, une pierre conique surmontée d'un bouton (hauteur : $74 \mathrm{~cm}$; diamètre : $42 \mathrm{~cm}$ ), un yoni composé de deux parties et deux grandes pierres rectangulaires $(127 \times 42 \times 20 \mathrm{~cm}$ et $132 \times 46 \times 34 \mathrm{~cm})$.

Lorsque Sri Soejatmi Satari visite le site en 1975, le lieu n'a guère changé, mais davantage de choses sont visibles. C'est elle qui nous donne la description la plus complète des vestiges (Sri Soejatmi Satari 1977 : 9). Le site serait composé de trois ensembles, distants les uns des autres d'environ $10 \mathrm{~m}$. Le premier ensemble, qui est encore visible aujourd'hui, comporte un yoni en deux parties et des fragments de pierre ${ }^{26}$. Le deuxième ensemble comporte un linteau de porte orné d'un $k \bar{a} l a$ et des pierres arrangées en carré ${ }^{27}$. Le troisième groupe est celui qui compte le plus de sculptures : un Ganeśa, une sorte de pierre de couronnement au sommet orné d'un lotus, une statue de taureau sans tête, deux hautes pierres en forme de padma, une pointe de dagob et un linga ${ }^{28}$.

25. Elle est en fait similaire à la modénature du yoni de Klawen (Bawang). Voir la note 30.

26. La partie inférieure du yoni est encore en place, la partie supérieure a disparu.

27. Le kāla en question est celui conservé devant le bureau du service du tourisme et de la culture de Batang. Voir ci-dessous.

28. Nous avons pu retrouver une partie de ces objets parmi les pièces conservées au musée Ronggowarsito et étiquetées comme provenant du desa Deles (Batang), en recoupant les informations tirées de la photographie que publie Sri Soejatmi Satari $(1977: 30)$ avec les dimensions des différentes pièces données par Goenadi Nitihaminoto et al. (1978:35-40). Les pierres en forme de padma sont en fait les pierres numérotées 04.00272 et 04.00275 . La pointe de dagob est le numéro 04.00261. Les lingas sont probablement ceux portant les numéros d'inventaire 04.00269 et 04.00270 . En revanche, nous n'avons pu identifier ni le Gaṇeśa ni le taureau. Dans l'inventaire du musée Ronggowarsito, quatre taureaux (04.00039;04.00040;04.00041;04.00042 [fig. 9]) sont pourtant répertoriés comme provenant du village de Deles, mais sans mention du nom du hameau. Une comparaison avec la photographie (de très 
En 1978, le site a fait l'objet de fouilles (Goenadi Nitihaminoto et al. 1978) : dix carrés de fouille de $2 \mathrm{~m}$ de côté ont ainsi été ouverts dans sa partie centrale. Les recherches ont mis au jour de nombreux fragments de pierre, quelques tessons de céramique, mais aucune sculpture. Les céramiques importées sont toutes largement postérieures à l'époque classique, les plus anciennes datant du XVII ${ }^{\mathrm{e}}$ siècle.

Aujourd'hui, les statues ne se trouvent plus sur place : il faut donc se fonder sur les observations faites dans les années 1970 pour se forger une idée de la nature du site. La présence de grandes pierres rectangulaires (probablement des parties d'encadrement de porte) et d'un linteau constituent des indices suffisants pour conclure à l'existence d'un temple. Au vu des yonis, linga, taureau et Ganeśa, on peut également affirmer qu'il s'agissait d'un monument hindou. Le linteau mentionné par Sri Soejatmi Satari, qui figure aussi sur les photos des dégagements de 1978, est désormais entreposé devant le bureau du service du tourisme et de la culture du district de Batang (fig. 10). Sa composition et son style sont typiques de la période de Java Centre. Le kāla est malheureusement incomplet (la partie supérieure est manquante) et abîmé, non seulement par l'usure du temps, mais aussi par de récentes coulées de ciment. L'absence de mâchoire inférieure, la relative simplicité de l'ornementation et le profil des enroulements végétaux qui bordent les côtés de la pierre rapprochent davantage ce kāla des exemplaires antérieurs au style de Loro Jonggrang (c. 850) ${ }^{29}$. Il est donc possible que le temple de Cepit ait été construit avant 850 .

Cepit n'est pas un site isolé, puisque deux autres sites, Kepyar et Klawen, ont été répertoriés dans les environs immédiats.

\section{Kepyar}

Le site de Kepyar se situe à environ $930 \mathrm{~m}$ d'altitude, sur une colline dominant la vallée de Bawang, en face de Cepit. Cette colline est longée à l'ouest par la rivière Belo et à l'est, par la rivière Putih.

L'endroit est aujourd'hui un cimetière musulman, mais on y trouve de nombreuses pierres de temple jonchant le sol et parfois réutilisées dans la construction des tombes (fig. 11-12). On observe un grand nombre de pierres rectangulaires, mais aussi des pierres à la stéréotomie plus complexe, des antéfixes, des pierres avec modénature et au moins une picrre de couronnement. Aucune des antéfixes encore visibles ne présente de décor, ce qui laisse penser que le temple n'a jamais été terminé.

Un linteau orné d'un kāla mesurant $117 \times 66 \mathrm{~cm}$ aurait également été trouvé à Kepyar (Data Peninggalan Batang 1985); il n'en existe malheureusement aucune photo.

\section{Klawen}

Le hameau de Klawen se trouve dans la vallée de Bawang, en contrebas des collines de Cepit et de Kepyar, à environ 840 m d'altitude. Il fait partie du village de Candigugur,

mauvaise qualité) publiée par Sri Soejatmi Satari nous fait conclure que le seul candidat valable est le taureau 04.00042. Nous discutons plus longuement de ce taureau ci-après, p. 364.

29. La dentition du kāla de Cepit est un peu inhabituelle. La plupart des käla possèdent deux grandes canines et nombre d'incisives, au profil plus plat et plus carré. Dans le cas de notre kāla, certes la taille des dents varie, mais leur forme est à peu près identique, si bien qu'il semble posséder non pas deux mais dix canines (deux grandes et huit petites). Une dentition similaire se retrouve sur plusieurs fragments provenant de Gedong Songo (photos OD 8997, 9000 et 9001) et de Ngawen (photo OD 7415), ainsi qu'à Kalasan. 
un nom qui peut se traduire par « le temple tombé (en ruines)». Le temple auquel le nom du village fait référence était vraisemblablement situé à Cepit ou à Kepyar.

Un yoni se trouvait autrefois devant une des maisons du village. Il a été transféré à Batang et se trouve aujourd'hui devant le bureau du service du tourisme et de la culture. Hormis des moulures, le piédestal ne présente aucune décoration. La modénature est assez particulière, puisque le schéma habituel (doucine, triple bandeau, panneau et pilastres, triple bandeau, doucine inversée) est remplacé par la succession d'une doucine, d'une série de trois triples bandeaux et d'une doucine renversée ${ }^{30}$.

Un linga (Data Peninggalan Batang 1985), deux yonis et une pierre de dépôt ou peripih (Goenadi Nitihaminoto $1978: 8$ ) auraient également été découverts dans le village de Candigugur. Le peripih est très vraisemblablement celui qui est entreposé au musée Ronggowarsito sous le numéro d'inventaire 04.00260 et enregistré comme provenant de "Bawang ». Il s'agit d'une pierre carrée de $22 \mathrm{~cm}$ de côté et $11 \mathrm{~cm}$ de haut, dans laquelle ont été creusés neuf petits compartiments mesurant 4,5 ×4,5 × 1,5 cm.

\section{Deles}

Non loin de Cepit, Kepyar et Klawen, au milieu d'une rizière, se trouve un autre site : Deles. Aujourd'hui, on ne peut y voir qu'un yoni et une pierre circulaire. En 1975, Sri Soejatmi Satari (1977: 10) avait encore pu y observer une sculpture, impossible à identifier à cause de l'érosion. Plusieurs pièces sont enregistrées dans l'inventaire du musée Ronggowarsito comme provenant de «Deles »; cependant il s'agit là du nom du desa (village) et non de celui du dusun/dukuh (hameau). Il y a toute raison de penser qu'une partie de ces pièces provient en fait de Cepit (desa Deles) ${ }^{31}$. Certaines d'entre elles ne peuvent en revanche être attribuées avec certitude à l'un ou l'autre site du desa de Deles (Cepit, Kepyar ou Deles) ; c'est pourquoi nous les mentionnons ici : c'est le cas de quatre sculptures représentant le taureau de Śiva, ainsi que d'un fragment de kāla. Deux de ces taureaux (04.00039 et 04.00041$)$ sont mutilés et fortement érodés.

Le troisième (04.00042 ; fig. 9) est d'excellente facture, comparable aux meilleurs exemplaires de la région de Yogyakarta. Sa pose est extrêmement naturaliste et ses yeux expriment une grande douceur. Le dernier taureau - qui est aussi celui qui a le plus de chances de provenir de Cepit et non de Deles - retient particulièrement l'attention en raison de l'inscription qu'il porte sur son socle. Cette brève inscription a été étudiée par A. Griffiths (2012:473-474), qui en donne la lecture, namaś sivāya jan(ma)cche(da), et la date paléographiquement du $\mathrm{VII}^{\mathrm{e}}$ ou du vIII ${ }^{\mathrm{e}}$ siècle.

La dernière pièce en provenance du desa Deles et conservée au musée Ronggowarsito $(04.00028$; fig. 14) est un bloc de pierre à peu près rectangulaire de $70 \times 44 \times 15 \mathrm{~cm}$, dont une face est sculptée. Au centre, en relief, on peut voir un rākșasa, reconnaissable à son épaisse chevelure, la jambe gauche repliée et la main gauche sur le genou, la main droite tenant une massue. Le fond du relief est entièrement occupé par un motif végétal. Sur la droite du rākşasa, on remarque toutefois les vestiges d'un $k \bar{a} l a:$ on distingue encore une patte, paume tournée vers l'avant, l'arrondi d'une joue et une partie d'oreille ou de corne. Une composition similaire se retrouve au candi Morangan (Klaten), un temple

30. Une modénature similaire se retrouve à Cepit (voir ci-dessus), sur un yoni qui fut découvert sur le plateau de Dieng (photo van Kinsbergen n" 113 ; photo OD 11292) ainsi que dans les temples de Kedulan et de Sambisari, près de Yogyakarta, ce qui pourrait suggérer une date relativement tardive, en seconde moitié du IX" siècle.

31. Voir la note 28 . 
généralement associé à la seconde moitié de la période de Java Centre. La présence d'une patte et, semble-t-il, d'une mâchoire inférieure rapproche le kāla de Deles de ceux du style de Loro Jonggrang et confirmerait donc une datation postérieure à 830 , voire postérieure à 850 de notre ère.

\section{Discussion}

La principale vertu de notre prospection dans le district de Batang est sans doute de montrer que l'inscription de Sejomerto, souvent citée par les historiens de Java pour son lien avec la dynastie des Śailendra, n'est pas une trouvaille isolée. Elle provient en fait d'une région bien plus riche en vestiges archéologiques que ne le laissaient penser les recherches précédentes.

\section{Distribution des sites}

Au sein du district de Batang, la plupart des sites archéologiques de la période hindobouddhique se trouvent dans les petites plaines et vallées de l'intérieur, principalement autour de Tersono, Bawang, Sejomerto et Blado. Ces régions correspondent également à des zones de sol volcanique, bien irriguées, mais à l'abri des grandes inondations contrairement aux basses terres du nord-ouest et du nord-est. Il y a donc sans doute à Batang, comme à Java Centre, une corrélation plus ou moins directe entre les implantations hindo-bouddhiques et la riziculture irriguée. Il reste cependant à déterminer si la quasi-absence de vestiges dans les plaines côtières est due à une volonté ancienne d'éviter les zones inondables et nécessitant des systèmes complexes de contrôle des eaux, à un déplacement important de la ligne de côte ou, plus prosaïquement, à la difficulté d'identifier des sites anciens sous d'épaisses couches d'alluvions.

Dans l'état de nos connaissances, il semble toutefois que la distribution des sites hindo-bouddhiques suive un schéma d'occupation privilégiant les moyennes vallées. Il existe bien sûr des exceptions, les plus notoires étant le groupe de vestiges autour de Simangli, dans la partie sud-ouest du district, les ruines de Sigemplong, au sud, ainsi que le site de Balekambang, près de la côte.

Les sites de Simangli, Pejati, Batur et Punden Wali Ajar Pendek sont situés dans une zone d'altitude qui reste, encore aujourd'hui, difficile d'accès. La région ne se prêtant pas non plus à la riziculture irriguée, il semble peu probable que ces vestiges correspondent à un peuplement important. Sans autres données tant textuelles que matérielles, il est difficile de se faire une idée de la fonction précise de ces implantations. Les sites reculés, dans les montagnes et les forêts, se voient souvent attribuer une fonction essentiellement religieuse : lieux de pèlerinage ou ermitages. L'hypothèse d'une implantation villageoise n'est toutefois pas à écarter. Dans une région du monde où les principaux objets d'échanges ont longtemps été les produits de la forêt, on aurait tort de ne pas considérer que ces sites d'altitude aient pu jouer un rôle dans la production économique.

La fonction de Sigemplong, que malheureusement nous n'avons pas pu visiter, mais qui a été décrit par les explorateurs néerlandais (Notulen $1867: 91-92 ; 1868 \mathrm{a}: 11 ; 1868 \mathrm{~b}$ : $23 ; 1871: 27$ ), semble assez clairement établie : il s'agit d'un escalier menant au plateau de Dieng. L'accès à Dieng via Batang n'est pas aisé, mais il est possible. Il se fait par un chemin qui, partant de Deles, suit une crête montagneuse entre les rivières Arus et Belo pour aboutir au village de Sigemplong. Là, la route se fait sentier. Une branche monte via les monts Sipandu et Pagerkandang et aboutit près du Telaga Merdada, à l'ouest de Dieng. L'autre branche longe le pied du mont Sipandu jusqu'au village de Rejosari et 
parvient à Dieng Kulon, non loin des temples du groupe d'Arjuna. Il est possible que Sigemplong fasse partie d'une ancienne route de pèlerinage menant de Deles à Dieng et que les vestiges de Deles, Cepit et Kepyar (voire même d'autres, plus en aval) en aient également fait partie. Il ne faudrait cependant pas réduire les sites du district de Batang à ce «chemin de Dieng ". D'une part, la distribution des sites dans les vallées d'altitude médiane et sans lien physique direct avec Dieng rend cette hypothèse peu probable. D'autre part, il faut s'interroger sur l'antériorité des vestiges. Dans l'état actuel des connaissances, les vestiges de Batang apparaissent comme plus anciens que ceux de Dieng. Il semble donc que la région de Batang ne se soit pas développée à cause de sa proximité avec le plateau. Il est probable, au contraire, que l'implantation hindo-bouddhique dans la région de Batang ait favorisé le développement du centre religieux de Dieng, tant le paysage de Batang est marqué par l'omniprésence du massif du Prahu et tant la mythification de ce géant de plus de $2500 \mathrm{~m}$ paraît naturelle.

Parmi les sites établis à l'extérieur de la zone la plus dense en vestiges classiques, celui qui retient le plus l'attention est celui de Balekambang. Balekambang est en effet le seul à se trouver (quasiment) en bord de mer. Le site est aujourd'hui à environ $1 \mathrm{~km}$ de la côte, près d'une source d'eau douce, au pied d'une colline qui le met à l'abri des inondations dont souffre la plaine alluviale. La rivière Anyar coule à quelques centaines de mètres plus à l'est et est encore utilisée comme point de mouillage pour les bateaux de pêche. Quant à la rivière Kuto, qui se trouve aujourd'hui à une distance de $2500 \mathrm{~m}$, il est possible qu'elle ait suivi, durant la période hindo-bouddhique, un cours plus proche de Balekambang. Les deux rivières donnent accès aux vallées de l'intérieur et, en particulier, aux zones de Tersono, Bawang et Sejomerto, qui sont également les plus riches en vestiges archéologiques. En réalité, la région de Balekambang est quasiment la seule à offrir tous ces avantages (accès aisé à la mer et aux terres, eau douce, terre ferme, point de mouillage) et il ne serait guère étonnant que les environs aient vu se développer un port à une époque ancienne.

\section{Chronologie de l'implantation}

Il est intéressant de noter que l'implantation hindo-bouddhique sur la côte et le long des principaux affluents de la Kuto a lieu dès le $\mathrm{VII}^{\mathrm{e}}-\mathrm{VIII}{ }^{\mathrm{e}}$ siècle. C'est du moins ce que semblent suggérer les premières études paléographiques des inscriptions. L'inscription de Balekambang daterait en effet du viI ${ }^{\mathrm{e}}$ siècle (Soekarto Kartoatmodjo, dans Goenadi Nitihaminoto et al. 1978 : 19 ; Griffiths 2012 : 474-477). Celles qui proviennent des vallées de l'arrière-pays remonteraient au VII ${ }^{\mathrm{e}}$ siècle pour Sojomerto (Boechari 1966 ; 2012 : 355), au VIII siècle pour Banjaran et au IX ${ }^{\mathfrak{e}}$ siècle pour Indrokilo (Griffiths 2012 : 479). Quant aux inscriptions de Deles (Griffiths 2012 : 473-474) et de Kepokoh (Machi Suhadi \& Soekarto 1986:3 ; Griffiths 2012:479), elles sont également datées de la même période, c'est-à-dire des $\mathrm{VII}^{\mathrm{c}}$-VIII' siècles. Il est possible que des sites n'ayant pas livré d'inscription remontent à la même époque, mais en l'absence de données issues de fouilles, il est encore impossible de l'affirmer. C'est peut-être le cas du site de Pejaten, avec ses Gaṇeśa à l'iconographie atypique et sa statue de Viṣnu/Hari-Hara, par exemple. Il est également difficile de préciser la durée d'occupation de la plupart des sites. Une chose est toutefois certaine : la région reste un creuset de la culture hindo-bouddhique durant toute la période de Java Centre. Le déménagement possible des Śailendra depuis Batang vers les plaines de Kedu et Yogyakarta n'a pas engendré l'abandon de la région. Les fondations religieuses y ont perduré au moins jusqu'à la seconde moitié du $I x^{\complement}$ siècle, 
comme en témoignent notamment les pièces de style tardif trouvées à Balekambang, Klenteng ou Deles.

Pour ce qui est de l'après $I X^{\mathrm{e}}-\mathrm{X}^{\mathrm{e}}$ siècles, les données sont insuffisantes. Un miroir en bronze découvert à Kanyaran témoigne d'une occupation de ce site au $\mathrm{XI}^{\mathrm{e}}-\mathrm{XII}^{\mathrm{e}}$ siècle ; des céramiques collectées en surface nous disent que Balekambang était en activité aux $\mathrm{XV}^{\mathrm{e}}-\mathrm{XVI}^{\mathrm{e}}$ siècles et Cepit, au XVII ${ }^{\mathrm{e}}$ siècle, ce qui n'apporte pas grand-chose à la discussion. Sans doute plus intéressante est la mention de plusieurs lieux de la région dans le poème sundanais du $\mathrm{XV}^{\mathrm{e}}-\mathrm{XVI} \mathrm{l}^{\mathrm{e}}$ siècle, lequel raconte le voyage de Bujangga Manik (lignes 750754 ; Noorduyn \& Teeuw $2006: 257$ ). Trois des noms mentionnés dans le texte peuvent encore être localisés (Noorduyn 1982 : 423) : Kupang (région du site de Watu Gajah), Batang et Tumerep (Tumbrep, le village où fut découverte l'inscription de Wutit).

\section{Traditions artistiques}

Parmi les sculptures d'époque hindo-bouddhique provenant du district de Batang, la vaste majorité relève sans surprise de la tradition de Java Centre. Certaines de ces sculptures peuvent paraître grossières, comme le taureau de Sidomulyo, mais d'autres, loin d'être des productions provinciales de second ordre, témoignent d'une grande maîtrise artistique. C'est notamment le cas des makaras et de la sculpture de Śrī provenant de Balekambang ou encore du fragment de linteau de Deles. Cela signifie que les responsables de ces fondations religieuses avaient le goût et les moyens de s'offrir les services d'artisans qualifiés, formés sur les chantiers de la vallée de la Progo ou des plaines du sud. De toute évidence, les monuments qu'ils ont construits à Batang n'avaient pas à pâlir devant ceux des régions plus proches du centre politico-culturel du royaume de Mataram.

Par ailleurs, certaines déviations du modèle de Java Centre apparaissent comme des tentatives mal maîtrisées. Nous le constatons par exemple sur le fragment de taureau de Sigit, pour lequel il y a certes eu un effort d'ornementation, mais dont l'aspect carré est quelque peu malheureux. En revanche, la statue de Durgā de Klenteng, dont il a été question plus haut, pourrait bien être la plus ancienne représentation de Durgā avec la main posée sur la tête de Mahiśa : elle constituerait donc une étape importante dans le développement de l'iconographie de la déesse, préfigurant les chefs-d'œuvre de l'époque de Singhasāri.

Mises à part les sculptures appartenant à la tradition de Java Centre, on trouve parmi les statues du district de Batang des représentations qui n'ont que peu d'équivalents en Indonésie. Nous ne reviendrons pas ici sur le cas des deux Ganeśa et du Hari-Hara de Pejaten, dont il nous semble devoir chercher la filiation en Inde et sur les côtes de l'Asie du Sud-Est continentale. Nous souhaitons attirer ici l'attention sur une œuvre tout aussi atypique, découverte à Kupang (Wonotunggal) et ayant déjà fait l'objet d'une étude iconographique (Sri Soejatmi Satari 1978 : 5-8). Il s'agit d'un bloc de pierre sculpté dans lequel l'archéologue indonésienne a reconnu la représentation de Viṣnu délivrant Gajendra. La majeure partie de la pierre est occupée par un relief d'éléphant. Entre les pattes de l'éléphant, on peut voir le corps, les bras et les jambes d'un personnage agenouillé. Sur la face gauche de la pierre, on distingue clairement une aile, d'où l'identification de ce personnage avec Garuḍa. Sur les épaules de Garuḍa, dont la tête a disparu, se trouve un second personnage, assis, dans lequel on doit sans doute reconnaître Viṣnu. Comme l'a noté Sri Soejatmi Satari, si l'iconographie est hindoue, le style rappelle la tradition mégalithique, et en particulier les sculptures de Pasemah. Il ne s'agit donc pas d'une représentation naturaliste, ni même logique : Garuḍa, qui devrait voler au-dessus de Gajendra, est visible des deux côtés de l'éléphant. Cette sculpture si particulière doit peut-être être 
replacée dans un contexte plus vaste d'interactions entre culture mégalithique et culture hindo-bouddhique. Il en va de même pour le site de Batur, où se mêlent tradition des punden en terrasses et religion hindoue. Ces deux sites semblent indiquer que la culture mégalithique, quelle que soit son ancienneté, a coexisté avec l'hindouisme, du moins dans la partie occidentale du district de Batang.

\section{Conclusion}

La région de Batang constitue dès le $\mathrm{VII}^{\mathrm{e}}$ siècle un centre important de culture hindobouddhique. Les inscriptions en sanskrit et en vieux malais, les sculptures d'influence indienne ou rappelant les statues de Cibuaya suggèrent que Batang faisait alors partie d'un réseau plus vaste, s'étendant sans doute de Bali à Sumatra, héritier de celui qui nous a laissé les fameux Viṣnu mitrés. Proche des montagnes et de leurs ressources en bois et produits précieux, riche d'un arrière-pays propice à la riziculture irriguée, la région offrait des avantages qui furent sans doute déterminants pour son développement. Peutêtre entrevoyons-nous ici un début de réponse à la question que se posait Wolters (1967). Batang pourrait bien être l'un de ces rivaux javanais auxquels le royaume naissant de Śrīvijaya tentait de s'opposer à la fin du vII ${ }^{\mathrm{e}}$ siècle.

\section{BIBLIOGRAPHIE}

\section{Baskoro Daru TJahjono}

2000 Budaya Marginal Masa Klasik di Jawa Tengah, Yogyakarta, Balai Arkeologi Yogyakarta (Berita Penelitian Arkeologi 12).

\section{BOECHARI}

1966 "Preliminary Report on the Discovery of an Old-Malay Inscription at Sodjomerto ", Madjalah Ilmu-Ilmu Sastra Indonesia 3, p. 241-251.

2012 " Preliminary Report on the Discovery of an Old-Malay Inscription at Sojomerto ", in Boechari, Melacak Sejarah Kuno Indonesia Lewat Prasasti: Tracing Ancient Indonesian History Through Inscriptions, Jakarta, Kepustakaan Populer Gramedia / École française d'Extrême-Orient, p. 349360 .

Brandes, Jan Laurens Andries

1904 «De verzameling gouden godenbeelden gevonden in het gehucht Gemoeroeh, bij Wanasaba: en naar aanleiding daarvan iets over Harihara en de geschiedenis van het uiterlijk van Garûda op Java », Tijdschrift voor Indische Taal-, Landen Volkenkunde 47, p. 552-577.

BRown, Robert L.

1987 «A Note on the Recently Discovered Ganeśa Image from Palembang, Sumatra ", Indonesia 43, p. 95-100.

Dalshfimer, Nadine \& Manguin, Pierre-Yves

1998 "Vișnu mitrés et réseaux marchands en Asie du Sud-Est : nouvelles données archéologiques sur le Ier millénaire apr. J.-C. ", Bulletin de l'École française d'Extrême-Orient 85, p. 87-123. 
DamaIS, Louis-Charles

1968 «Bibliographie indonésienne. XI. Les publications épigraphiques du service archéologique de l'Indonésie ", Bulletin de l'École française d'ExtrêmeOrient 54, p. 295-521.

Data Pininggalan Batang

1985 Data Muskala 1984/1985. Data Peninggalan Sejarah dan Purbakala Jawa Tengah. Keadaan Tahun 1984/1985, Batang, Kantor Depdikbud (rapport non publié).

EDI SEDYaWATI

1994 Ganeśa statuary of the Kaḍiri and Sinhasāri periods, Leiden, KITLV Press (Verhandelingen van het Koninklijk Instituut voor Taal-, Land- en Volkenkunde 160).

FONTEIN, Jan

1990 The Sculpture of Indonesia, Washington / New York, National Gallery of Art / Harry N. Abrams.

Goenadi Nitihaminoto, Soekarto Kartoatmodjo, Pubroto, Sumiati Atmosudiro, Riboet Darmosoltopo, Susanto, Moflyadi \& Blidinto

1978 Laporan Ekskavasi Deles, Jawa Tengah. 18 Maret s-d 7 April 1978, Yogyakarta, Proyek Penelitian dan Penggalian Purbakala Daerah Istimewa Yogyakarta (rapport non publié).

GrifFITHS, Arlo

2012 "The epigraphical collection of Museum Ranggawarsita in Semarang (Central Java, Indonesia) ", Bijdragen tot de Taal-, Land-en Volkenkunde 168/4, p. 472-496.

Groenevfldt, Willem Pieter

1887 Catalogus der archeologische verzameling van het Bataviaasch Genootschap van Kunsten en Wetenschappen, Batavia, Albrecht \& co.

Hermawanti \& Kussunartini Y. M.

2000 Arca Perunggu Koleksi Museum Negeri Provinsi Jawa Tengah Ronggowarsito, Semarang, Museum Negeri Provinsi Jawa Tengah Ronggowarsito.

Krom, Nicolaas Johannes

1914 "Inventaris der Hindoe-oudheden op den grondslag van Dr. R.O.M. Verbeek's Oudheden van Java », Rapporten van den Oudheidkundigen Dienst in Nederlandsch-Indië 1.

Kusnin Asa, Haris Sukendar, Machi Suhadi \& Suharto

2011 Sejarah Budaya Batang, Batang, Dinas Kebudayaan dan Pariwisata Kabupaten Batang.

Lunsingh SCHEurleER, Pauline \& Klokke, Marijke J.

1988 Divine Bronze. Ancient Indonesian Bronzes from A.D. 600 to 1600, Leiden, Brill.

Machi Suhadi \& Soekarto Kartoatmodio

1986 Laporan Penelitian Epigrafi Jawa Tengah, Jakarta, Proyek Penelitian Purbakala Jakarta (Berita Penelitian Arkeologi 37). 
M(KINNon, Edwards E.

1985 «Early Polities in Southern Sumatra: Some Preliminary Observations Based on Archaeological Evidence », Indonesia 40, p. 1-36.

Muhammad Hidayat

1994 Laporan Peninjauan Arkeologi : Peninjauan Kepurbakalaan di Wilayah Kabupaten Batang dan Pekalongan (17-20 Februari 1994), Yogyakarta, Balai Arkeologi Yogyakarta (rapport non publié).

NOORILYN, Jacobus

1982 «Bujangga Manik's Journeys through Java: Topographical Data from an Old Sundanese Source ", Bijdragen tot de Taal-, Land- en Volkenkunde 138/4, p. 413-442.

NoOrduYn, Jacobus \& Til:L'w, Andries

2006 Three Old Sundanese Poems, Leiden, KITLV Press.

NotuleN

1867 «Vergadering der Directie op Dinsdag 30 October 1867, des avonds ten acht ure, in de vergaderzaal de Koninklijke Natuurkundige vereeniging ", Notulen van de Algemeene en Bestunirs-vergaderingen van het Bataviaasch Genootschap van Kunsten en Wetenschappen 5, p. 86-97.

1868a «Vergadering der Directie op Dinsdag 14 Januari 1868, des avonds ten 8 ure », Notulen van de Algemeene en Bestuurs-vergaderingen van het Bataviaasch Genootschap van Kunsten en Wetenschappen 6, p. 1-12.

$1868 \mathrm{~b}$ " Vergadering der Directie op Dinsdag 31 Maart 1868, des avonds ten 8 ure ", Notulen van de Algemeene en Bestuurs-vergaderingen van het Bataviaasch Genootschap van Kunsten en Wetenschappen 6, p. 20-33.

1872 "Bestuurs-vergadering van Dinsdag, 1 October 1872 des avonds te 8 uren ", Notulen van de Algemeene en Bestuurs-vergaderingen van het Bataviaasch Genootschap van Kunsten en Wetenschappen 10, p. 125-135.

1873 " Bestuurs-vergadering van Dinsdag, 19 Augustus 1873 des avonds te 8 uren ", Notulen van de Algemeene en Bestuurs-vergaderingen van het Bataviaasch Genootschap van Kunsten en Wetenschappen 11, p. 93-124.

1887a "Bestuursvergadering van Dinsdag, 5 April 1887 ", Notulen van de Algemeene en Bestuursvergaderingen van het Bataviaasch Genootschap van Kunsten en Wetenschappen 25, p. 47-58.

1887b " Bestuursvergadering van Dinsdag, 10 Mei 1887 ", Notulen van de Algemeene en Bestunrsvergaderingen van het Bataviaasch Genootschap van Kunsten en Wetenschappen 25, p. 59-80.

$1887 \mathrm{c}$ «Bestuursvergadering van Dinsdag, 5 Juli $1887 »$, Notulen van de Algemeene en Bestuursvergaderingen van het Bataviaasch Genootschap van Kunsten en Wetenschappen 25, p. 95-109.

$1887 \mathrm{~d}$ « Lijst der voorwerpen, die in het jaar 1887 voor de archeologische verzameling zijn verkregen ", Notulen van de Algemeene en Bestuursvergaderingen van het Bataviaasch Genootschap van Kunsten en Wetenschappen 25, bijlage VI, p. XLIII-LXI.

1899a "Directievergadering van Woensdag 4 Januari 1899 ", Notulen van de Algeme'ene' e'n Directievergaderingen van het Bataviaasch Genootschap van Kunsten en Wetenschappen 37, p. 1-13. 
$1899 \mathrm{~b}$ " Directievergadering van Maandag 6 Maart 1899 ", Notulen van de Algemeene en Directievergaderingen van het Bataviaasch Genootschap van Kunsten en Wetenschappen 37, p. 46-72.

1899c «Lijst dervoorwerpen, die in het jaar 1899 voor de archeologische verzameling zijn verkregen ", Notulen van de Algemeene en Directievergaderingen van het Bataviaasch Genootschap van Kunsten en Wetenschappen 37, bijlage XX, p. CXXXIII-CLXXI.

1903a « Notulen van de zesde Directievergadering, gehouden op Vrijdag den 9en October 1903 ", Notulen van de Algemeene en Directievergaderingen van het Bataviaasch Genootschap van Kunsten en Wetenschappen 41, p. 94-114.

1903b «Lijstdervoorwerpen, die in hetjaar 1903 voor de Archaeologische Verzameling zijn verkregen ", Notulen van de Algemeene en Directievergaderingen van het Bataviaasch Genootschap van Kunsten en Wetenschappen 41, bijlage XII, p. LXXXVIII-CVIII.

RAFFLES, Thomas Stamford

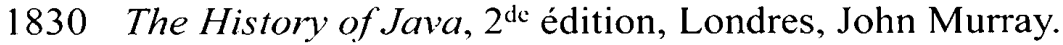

SFlu, E. A.

1912 «Opgave der Hindoe-oudheden in de Residentie Pekalongan (met uitzondering van de afdeeling Brěběs) ", Rapporten van de commissie in NederlandschIndië voor oudheidkundig onderzoek op Java en Madoera, p. 153-200.

SoEkARto Kartoatmodjo

1994 «Beberapa Temuan Prasasti Baru di Indonesia », Berkala Arkeologi 14, p. $1-5$.

SOFWAN NOERWIDI

2007 «Melacak Jejak Awal Indianisasi di Pantai Utara Jawa Tengah », Berkala Arkeologi 27, p. 40-65.

SRi Soejatmi Satari

1977 Survai di Kabupaten Pekalongan, Batang dan Kendal, Jakarta, Pusat Penelitian Purbakala dan Peninggalan Nasional (Berita Penelitian Arkeologi 9).

1978 New Finds in Northern Central Java, Jakarta, Pusat Penelitian Purbakala dan Peninggalan Nasional (Bulletin of the Research Centre of Archaeology of Indonesia 13).

Tim Penelitian Balai Arkeologi Yogyakarta

2010 Jejak-Jejak Awal Masuknya Budaya Hindu-Buddha di Jawa. Kebupaten Batang dan Sekiternya - Jawa Tengah, Dinas Kebudayaan dan Pariwisata Propinsi Jawa Tengah.

Verbeek, Rogier Diederik Marius

1891 Oudheden van Java : lijst der voornaamste overblijfselen uit den Hindoetijd op Java, met eene oudheidkundige kaart, Batavia / 'Hage, Landsdrukkerij / Nijhoff (Verhandelingen van het Bataviaasch Genootschap van Kunsten en Wetenschappen 46).

WOLTERS, Oliver W.

1967 Early Indonesian Commerce: A Study of the Origins of Srivijaya, Ithaca / New York, Cornell University Press. 


\section{APPENDICE}

\section{Liste des sites archéologiques du district de Batang ${ }^{32}$}

\begin{tabular}{|c|c|c|c|}
\hline Nom du site & $\begin{array}{l}\text { Localisation } \\
\text { administrative }\end{array}$ & $\begin{array}{l}\text { Coordonnées } \\
\text { géographiques }\end{array}$ & Description \\
\hline Kanyaran* & $\begin{array}{l}\text { Kanyaran, Simpar, } \\
\text { Bandar }\end{array}$ & $\begin{array}{l}06^{\circ} 59^{\prime} 30^{\prime \prime} \mathrm{S} ; 109^{\circ} \\
46^{\prime} 30^{\prime \prime} \mathrm{E}\end{array}$ & $\begin{array}{l}\text { bol et plats en bronze, } \\
\text { manches de miroir, bijoux, } \\
\text { céramiques }\end{array}$ \\
\hline Kebonbatur ${ }^{*}$ & $\begin{array}{l}\text { Kebonbatur, Wonomerto, } \\
\text { Bandar }\end{array}$ & $\begin{array}{l}07^{\circ} 04^{\prime} 45^{\prime \prime} \mathrm{S} ; 109^{\circ} \\
47^{\prime} 15^{\prime \prime} \mathrm{E}\end{array}$ & yoni \\
\hline Proto & $\begin{array}{l}\text { Proto, Tambahrejo, } \\
\text { Bandar }\end{array}$ & $\begin{array}{l}07^{\circ} 01^{\prime} 18^{\prime \prime} \mathrm{S} ; 109^{\circ} \\
46^{\prime} 59,5{ }^{\prime \prime} \mathrm{E}\end{array}$ & yoni \\
\hline Wutit & $\begin{array}{l}\text { Tumbrep, Tumbrep, } \\
\text { Bandar }\end{array}$ & $\begin{array}{l}07^{\circ} 03 ' 23.6 " \mathrm{~S} ; \\
109^{\circ} 48 ' 47.9 " \mathrm{E}\end{array}$ & $\begin{array}{l}\text { taureau, bornes en pierre, } \\
\text { mortier, inscription }\left(\mathrm{IX}^{\mathrm{e}}-\mathrm{X}^{\mathrm{e}} \mathrm{s} \text {. }\right.\end{array}$ \\
\hline Kedongdong $^{*}$ & $\begin{array}{l}\text { Kedongdong, } \\
\text { Kedawung, Banyuputih }\end{array}$ & $\begin{array}{l}06^{\circ} 56^{\prime} 30^{\prime \prime} \mathrm{S} ; 109^{\circ} \\
55^{\prime} 00^{\prime \prime} \mathrm{E}\end{array}$ & talams \\
\hline Penundan* & $\begin{array}{l}\text { Penundan, Penundan, } \\
\text { Banyuputih }\end{array}$ & $\begin{array}{l}06^{\circ} 57^{\prime} 30^{\prime \prime} \mathrm{S} ; 109^{\circ} \\
57^{\prime} 30^{\prime \prime} \mathrm{E}\end{array}$ & yonis \\
\hline Banaran* & $\begin{array}{l}\text { Banaran, Gunungsari, } \\
\text { Bawang }\end{array}$ & $\begin{array}{l}07^{\circ} 07^{\prime} 40.3 ", \mathrm{~S} \\
109^{\circ} 55^{\prime} 09,8, \mathrm{E}\end{array}$ & borne linga, taureau \\
\hline Cepit & Cepit, Deles, Bawang & $\begin{array}{l}07^{\circ} 07^{\prime} 18.5^{\prime \prime} \mathrm{S} ; \\
109^{\circ} 54^{\prime} 26.8^{\prime \prime} \mathrm{E}\end{array}$ & $\begin{array}{l}\text { pierres de taille, Gaṇeśa, } \\
\text { taureau, linga, kāla }\end{array}$ \\
\hline Deles & Deles, Deles, Bawang & $\begin{array}{l}07^{\circ} 06^{\prime} 43,99^{\prime \prime} \mathrm{S} ; \\
109^{\circ} 54^{\prime} 26,44^{\prime \prime} \mathrm{E}\end{array}$ & $\begin{array}{l}\text { yoni, taureau, kāla, } \\
\text { inscription }\left(\mathrm{VII}^{\mathrm{e}}-\mathrm{VIII} \mathrm{e} \text { s.) }\right.\end{array}$ \\
\hline Kepyar & Kepyar, Deles, Bawang & $\begin{array}{l}07^{\circ} 07^{\prime} 20.1 " ' \mathrm{~S} ; \\
109^{\circ} 54^{\prime} 52,1^{\prime \prime} \mathrm{E}\end{array}$ & pierres de taille, kāla \\
\hline Klawen* & $\begin{array}{l}\text { Klawen, Candigugur, } \\
\text { Bawang }\end{array}$ & $\begin{array}{l}07^{\circ} 06 ’ 29.1 " \mathrm{~S} ; \\
109^{\circ} 54^{\prime} 44.1 " \mathrm{E}\end{array}$ & yonis, linga, peripih \\
\hline Klenteng & $\begin{array}{l}\text { Klenteng, Sibebek, } \\
\text { Bawang }\end{array}$ & $\begin{array}{l}07^{\circ} 04^{\prime} 49.3 \prime \prime \mathrm{S} \\
109^{\circ} 54^{\prime} 58^{\prime \prime} \mathrm{E}\end{array}$ & $\begin{array}{l}\text { yonis, Agastya, Nandīśvara, } \\
\text { Durgā }\end{array}$ \\
\hline Ngreco & $\begin{array}{l}\text { Ngreco, Gunungsari, } \\
\text { Bawang }\end{array}$ & $\begin{array}{l}07^{\circ} 07^{\prime} 58.7^{\prime \prime} \mathrm{S} ; \\
109^{\circ} 55^{\prime} 00.6 " \mathrm{E}\end{array}$ & yonis, Gaṇeśa \\
\hline Purbo* & Purbo, Purbo, Bawang & $\begin{array}{l}07^{\circ} 05^{\prime} 09.9^{\prime \prime} \mathrm{S} ; \\
109^{\circ} 55^{\prime} 56.1^{\prime \prime} \mathrm{E}\end{array}$ & lingas \\
\hline Sigemplong & $\begin{array}{l}\text { Sigemplong, Pranten, } \\
\text { Bawang }\end{array}$ & $\begin{array}{l}7^{\circ} 10^{\prime} 30^{\prime \prime} \mathrm{S} ; 109^{\circ} \\
53^{\prime} 45^{\prime \prime} \mathrm{E}\end{array}$ & escalier \\
\hline Sigong & $\begin{array}{l}\text { Kebaturan, Kebaturan, } \\
\text { Bawang }\end{array}$ & $\begin{array}{l}07^{\circ} 07^{\prime} 47.6 ” \mathrm{~S} ; \\
109^{\circ} 56^{\prime} 10.99^{\prime \prime} \mathrm{E}\end{array}$ & yonis, gongs de pierre \\
\hline Kalirejo & $\begin{array}{l}\text { Kalirejo, Selopanjang } \\
\text { Timur, Blado }\end{array}$ & $\begin{array}{l}07^{\circ} 03 ' 34.8 " \mathrm{~S} ; \\
109^{\circ} 51 ' 15.9^{\prime \prime} \mathrm{E}\end{array}$ & mortier, taureaux, piédestal \\
\hline Kepokoh & Kepokoh, Blado, Blado & $\begin{array}{l}07^{\circ} 04^{\prime} 24.8^{\prime \prime} \mathrm{S} ; \\
109^{\circ} 49^{\prime} 44.1 " \mathrm{E}\end{array}$ & yoni, inscription $\left(\mathrm{VII}^{\mathrm{e}}-\mathrm{VIII}^{\mathrm{e}} \mathrm{s}\right.$. \\
\hline
\end{tabular}




\begin{tabular}{|c|c|c|c|}
\hline Balekambang & $\begin{array}{l}\text { Bendosari, Sidorejo, } \\
\text { Gringsing }\end{array}$ & $\begin{array}{l}06^{\circ} 56^{\prime} 11.5, \mathrm{~S} ; \\
110^{\circ} 00^{\prime} 37^{\prime \prime} \mathrm{E}\end{array}$ & $\begin{array}{l}\text { pierres de taille, inscription } \\
\left(\mathrm{VII}^{\mathrm{e}} \mathrm{s} .\right), n a \bar{g} a \text {, oies, makara, } \\
\text { Śrī, céramiques }\left(\mathrm{XV}^{\mathrm{e}}-\mathrm{XVI}^{\mathrm{e}} \mathrm{s} \text {.) }\right.\end{array}$ \\
\hline Medono & $\begin{array}{l}\text { Medono, Plumbon, } \\
\text { Limpung }\end{array}$ & $\begin{array}{l}07^{\circ} 01^{\prime} 35.2 ", \mathrm{~S} ; \\
109^{\circ} 566^{\prime} 26.5 " \mathrm{E}\end{array}$ & piédestaux \\
\hline Indrokilo* & $\begin{array}{l}\text { Indrokilo, Gemuh, } \\
\text { Pecalungan }\end{array}$ & $\begin{array}{l}07^{\circ} 03 ' 47.3 ", \mathrm{~S} ; \\
109^{\circ} 51 ' 40.8, ' \mathrm{E}\end{array}$ & inscription $(\mathrm{IX} \mathrm{e} s)$. \\
\hline Sigit & $\begin{array}{l}\text { Sigit, Pecalungan, } \\
\text { Pecalungan }\end{array}$ & $\begin{array}{l}07^{\circ} 00^{\prime} 50.7 ", \mathrm{~S} ; \\
109^{\circ} 50^{\prime} 49.2 " \mathrm{E}\end{array}$ & $\begin{array}{l}\text { fondation, taureau, Gaṇeśa, } \\
\text { céramiques (IX } \mathrm{s} \text {.) }\end{array}$ \\
\hline Banjaran $^{*}$ & $\begin{array}{l}\text { Banjaran, Mampir, } \\
\text { Reban }\end{array}$ & $\begin{array}{l}07^{\circ} 03^{\prime} 01.1^{\prime \prime} \mathrm{S} \\
109^{\circ} 52^{\prime} 23.7^{\prime \prime} \mathrm{E}\end{array}$ & inscription $\left(\mathrm{VIII}^{\mathrm{e}} \mathrm{s}.\right)$ \\
\hline Kalisari & Kalisari, Kalisari, Reban & $\begin{array}{l}07^{\circ} 04^{\prime} 17.5{ }^{\prime \prime} \mathrm{S} \\
109^{\circ} 54^{\prime} 45^{\prime \prime} \mathrm{E}\end{array}$ & pierres de taille, yoni \\
\hline Pengilon & $\begin{array}{l}\text { Pengilon, Kumesu, } \\
\text { Reban }\end{array}$ & $\begin{array}{l}07^{\circ} 04 ' 10.6 " \mathrm{~S} ; \\
109^{\circ} 54^{\prime} 02.1, \mathrm{E}\end{array}$ & yoni, linga, taureau \\
\hline Polodoro & $\begin{array}{l}\text { Polodoro, Polodoro, } \\
\text { Reban }\end{array}$ & $\begin{array}{l}07^{\circ} 02 ' 58.4^{\prime \prime} \mathrm{S} ; \\
109^{\circ} 534^{\prime} 54^{\prime \prime} \mathrm{E}\end{array}$ & $\begin{array}{l}\text { bronzes }\left(\mathrm{IX}^{\mathrm{e}}-\mathrm{X}^{\mathrm{e}} \mathrm{s} .\right) \\
\text { céramique }\left(\mathrm{X}^{\mathrm{e}} \mathrm{s} .\right)\end{array}$ \\
\hline Sejomerto & $\begin{array}{l}\text { Sejomerto, Sejomerto, } \\
\text { Reban }\end{array}$ & $\begin{array}{l}07^{\circ} 02^{\prime} 29.4 " \mathrm{~S} ; \\
109^{\circ} 533^{\prime} 58.5^{\prime \prime} \mathrm{E}\end{array}$ & inscription $\left(\mathrm{V}^{\prime} \mathrm{I}^{\mathrm{e}} \mathrm{s}.\right)$ \\
\hline Sidomulyo & $\begin{array}{l}\text { Sidomulyo, Adinuso, } \\
\text { Reban }\end{array}$ & $\begin{array}{l}07^{\circ} 05^{\prime} 43^{\prime \prime} \mathrm{S} ; 109^{\circ} \\
53^{\prime} 16.5{ }^{\prime \prime} \mathrm{E}\end{array}$ & $\begin{array}{l}\text { pierres de taille, piédestal, } \\
\text { taureau }\end{array}$ \\
\hline Klebut & $\begin{array}{l}\text { Klebut, Kemiri Barat, } \\
\text { Subah }\end{array}$ & $\begin{array}{l}06^{\circ} 57 ' 19.6 " \mathrm{~S} ; \\
109^{\circ} 53,48.1 " \mathrm{E}\end{array}$ & yoni, linga \\
\hline Kauman & $\begin{array}{l}\text { Kauman, Tersono, } \\
\text { Tersono }\end{array}$ & $\begin{array}{l}07^{\circ} 01^{\prime} 13.7^{\prime \prime} \mathrm{S} ; \\
109^{\circ} 67^{\prime} 37.9^{\prime \prime} \mathrm{E}\end{array}$ & linteau, taureau \\
\hline Pejambon & $\begin{array}{l}\text { Pejambon, Rejosari } \\
\text { Barat, Tersono }\end{array}$ & $\begin{array}{l}07^{\circ} 02{ }^{\prime} 14.8, \mathrm{~S} ; \\
109^{\circ} 57^{\prime} 19.1 " \mathrm{E}\end{array}$ & yonis, poutres \\
\hline Pejaten & $\begin{array}{l}\text { Pejaten, Rejosari, } \\
\text { Tersono }\end{array}$ & $\begin{array}{l}07^{\circ} 01 ' 33.8 ” \mathrm{~S} ; \\
109^{\circ} 57^{\prime} 07.9^{\prime \prime} \mathrm{E}\end{array}$ & $\begin{array}{l}\text { briques, pierre gravée, } \\
\text { Gaṇeśa, taureau, pierres de } \\
\text { taille, Viṣṇu ou Hari-Hara }\end{array}$ \\
\hline Silarun & $\begin{array}{l}\text { Bandungsari, Rejosari } \\
\text { Timur, Tersono }\end{array}$ & $\begin{array}{l}07^{\circ} 02^{\prime} 23.9^{\prime \prime} \mathrm{S} ; \\
109^{\circ} 57^{\prime} 23.1 " \mathrm{E}\end{array}$ & Gaṇeśa \\
\hline Wanar & Wanar, Wanar, Tersono & $\begin{array}{l}07^{\circ} 03 ’ 35.6 " \mathrm{~S} ; \\
109^{\circ} 57 ' 32.0 " \mathrm{E}\end{array}$ & céramiques (IX $\left.{ }^{\mathrm{e}} \mathrm{S}.\right)$, bronzes \\
\hline Gapuro & $\begin{array}{l}\text { Gapuro, Gapuro, } \\
\text { Warungasem }\end{array}$ & $\begin{array}{l}06^{\circ} 56^{\prime} 26.7 " \mathrm{~S} ; \\
109^{\circ} 400^{\prime} 35.99^{\prime \prime} \mathrm{E}\end{array}$ & yonis \\
\hline Arca Simangli & $\begin{array}{l}\text { Simangli, Silurah, } \\
\text { Wonotunggal }\end{array}$ & $\begin{array}{l}07^{\circ} 04 ' 37.7 \prime, \mathrm{S} ; \\
109^{\circ} 45^{\prime} 27.4, \mathrm{E}\end{array}$ & $\begin{array}{l}\text { Gaṇeśa, sculpture, pierres } \\
\text { de taille }\end{array}$ \\
\hline Batur & $\begin{array}{l}\text { Batur, Silurah, } \\
\text { Wonotunggal }\end{array}$ & $\begin{array}{l}07^{\circ} 05^{\prime} 05.2, \mathrm{~S} ; \\
109^{\circ} 46^{\prime} 06.1 " \mathrm{~S}\end{array}$ & punden, yoni, Gaṇeśa \\
\hline Pejati & $\begin{array}{l}\text { Pejati, Silurah, } \\
\text { Wonotunggal }\end{array}$ & $\begin{array}{l}07^{\circ} 05^{\prime} 58.1 ", \mathrm{~S} ; \\
109^{\circ} 46^{\prime} 08.9{ }^{\prime \prime} \mathrm{E}\end{array}$ & linga, yoni \\
\hline $\begin{array}{l}\text { Punden Wali } \\
\text { Ajar Pendek }\end{array}$ & $\begin{array}{l}\text { Batur, Silurah, } \\
\text { Wonotunggal }\end{array}$ & $\begin{array}{l}07^{\circ} 05^{\prime} 07.3 " \mathrm{~S} ; \\
109^{\circ} 46^{\prime} 10.5 " \mathrm{E}\end{array}$ & punden \\
\hline Simangli & $\begin{array}{l}\text { Simangli, Silurah, } \\
\text { Wonotunggal }\end{array}$ & $\begin{array}{l}07^{\circ} 05^{\prime} 19.3, \mathrm{~S} ; \\
109^{\circ} 45^{\prime} 38.5, \mathrm{E}\end{array}$ & linga, yonis \\
\hline Sodong & $\begin{array}{l}\text { Sodong, Sodong, } \\
\text { Wonotunggal }\end{array}$ & $\begin{array}{l}07^{\circ} 03 ’ 50.5 " \mathrm{~S} ; \\
109^{\circ} 46,09.7 " \mathrm{E}\end{array}$ & yoni, talam, Gaṇeśa \\
\hline Watu Gajah & $\begin{array}{l}\text { Kupang, Brokoh, } \\
\text { Wonotunggal }\end{array}$ & $\begin{array}{l}06^{\circ} 59^{\prime} 56.5^{\prime \prime} \mathrm{S} ; \\
109^{\circ} 44^{\prime} 22.6^{\prime \prime} \mathrm{S}\end{array}$ & $\begin{array}{l}\text { yoni, dvarapala, éléphant, } \\
\text { fondation }\end{array}$ \\
\hline
\end{tabular}




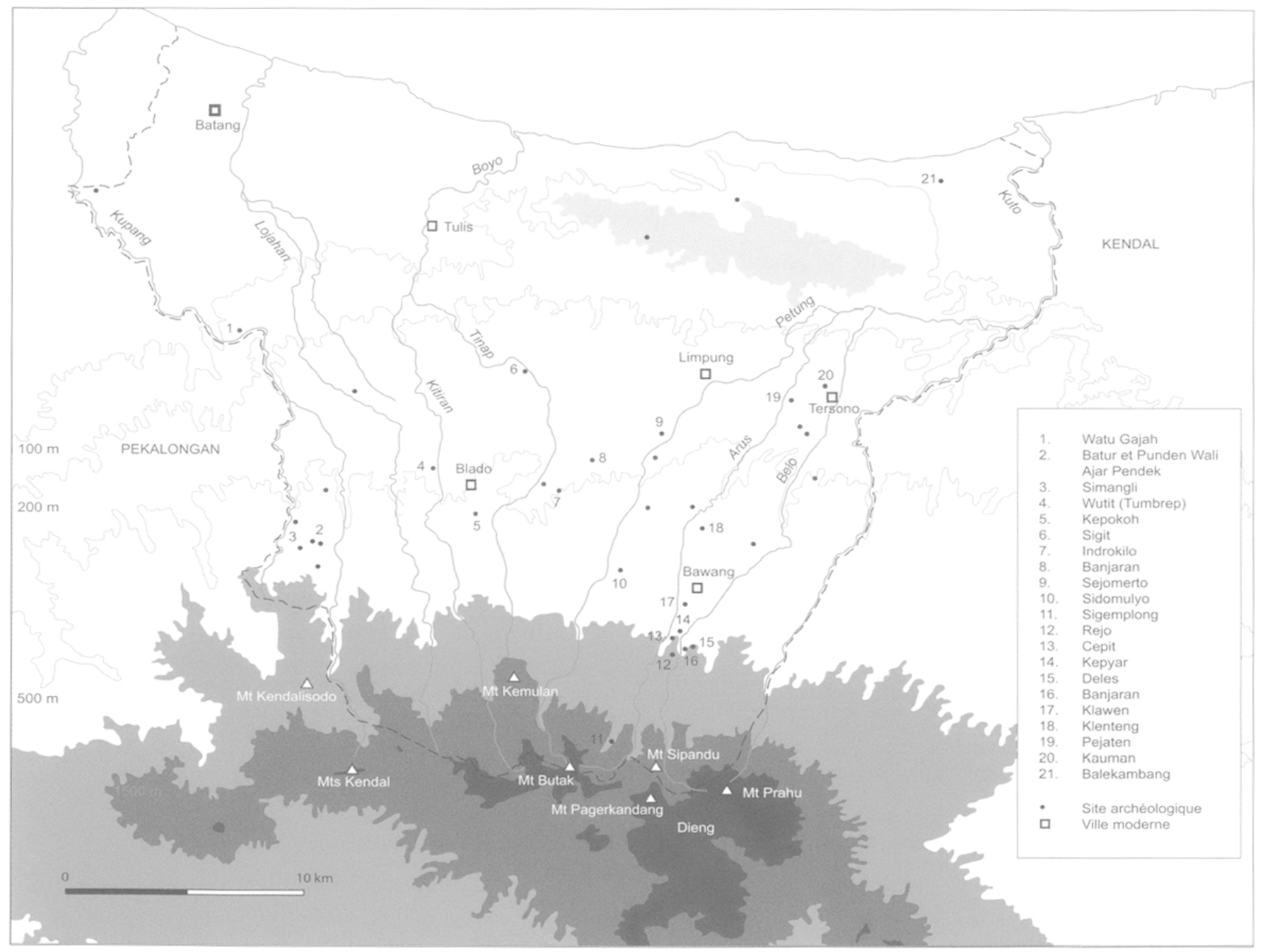

Figure 1 : Carte archéologique du district de Batang, avec localisation des sites mentionnés dans le texte. 


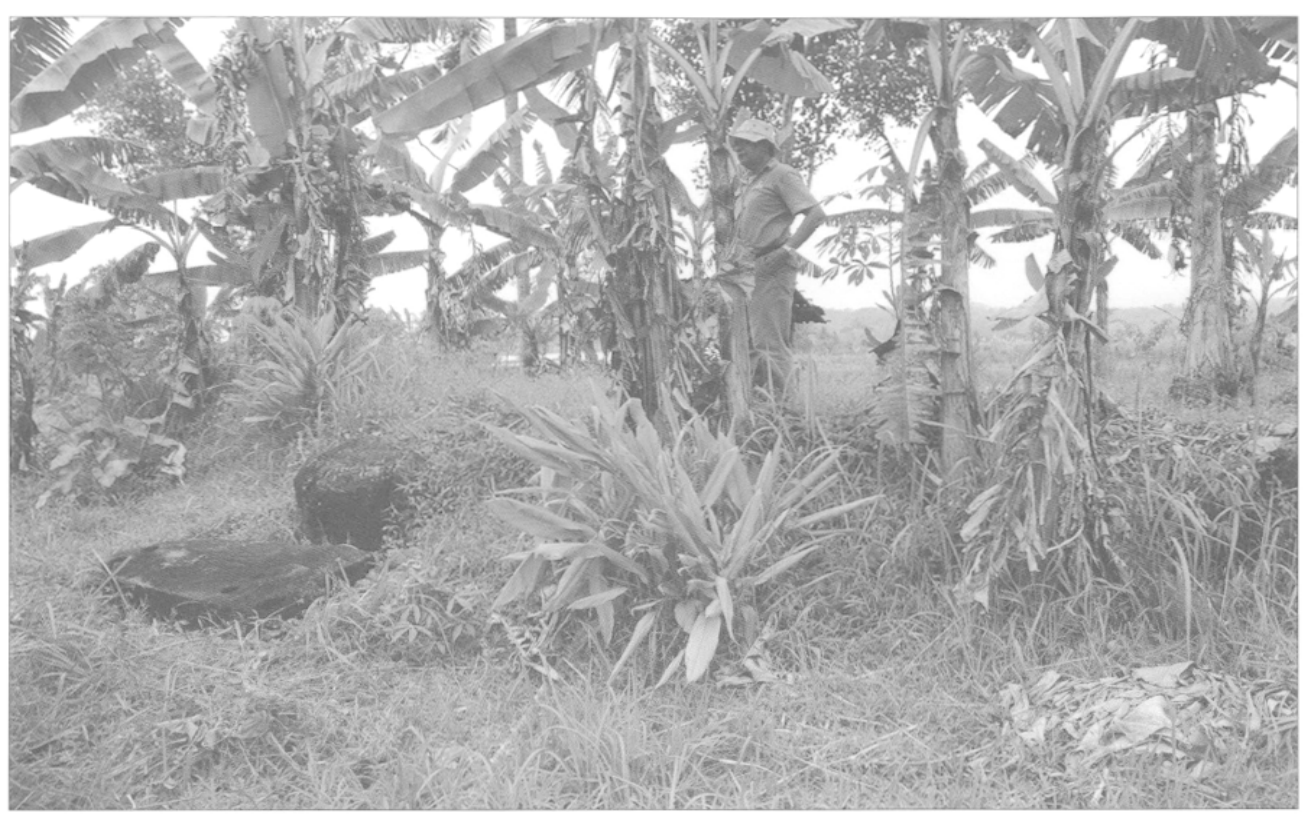

Figure 2 : Sigit, tertre marquant l'emplacement d'une structure. Sur la gauche, on aperçoit une pierre de seuil.

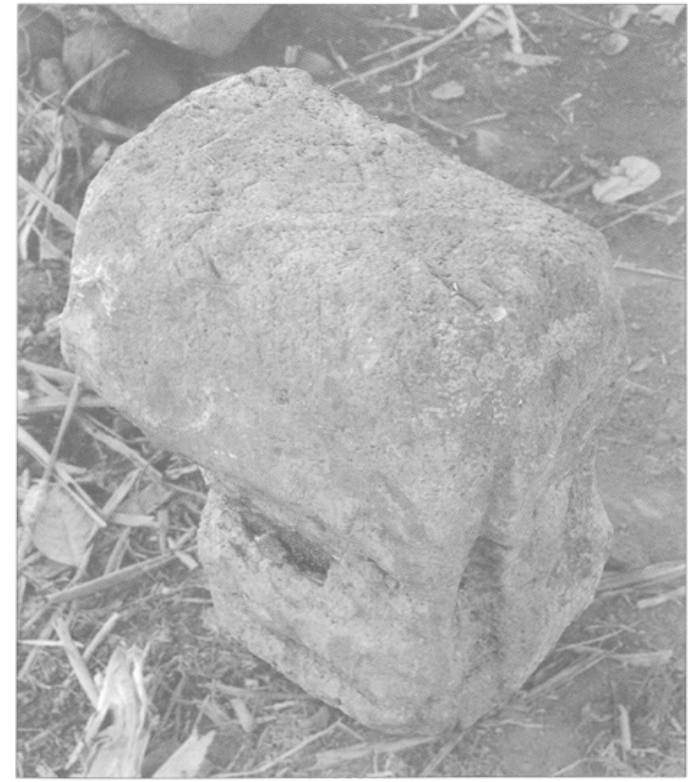

Figure 3 : Sigit, fragment de taureau découvert sur le tertre.

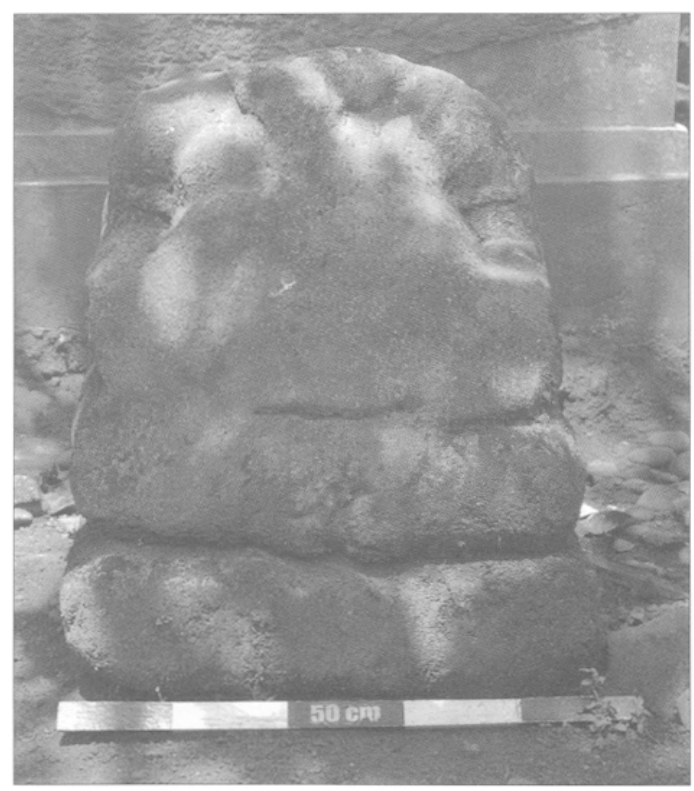

Figure 4 : Ganeśa en provenance de Sigit, aujourd'hui devant une maison du village de Siguci. 


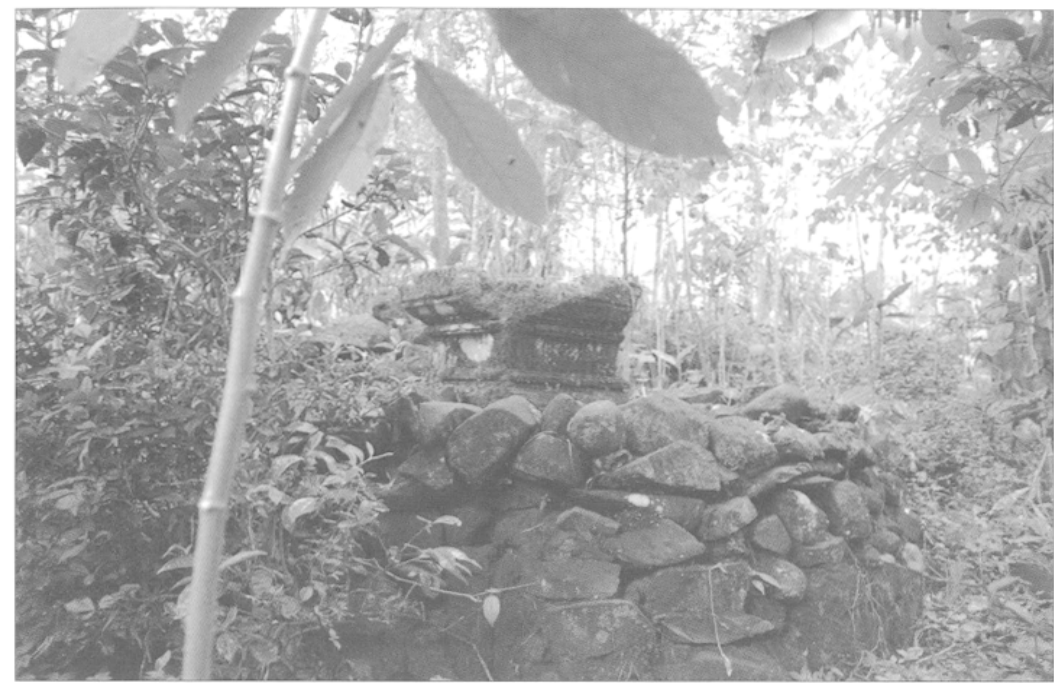

Figure 5 : Batur, vue de la deuxième terrasse du punden et du yoni.

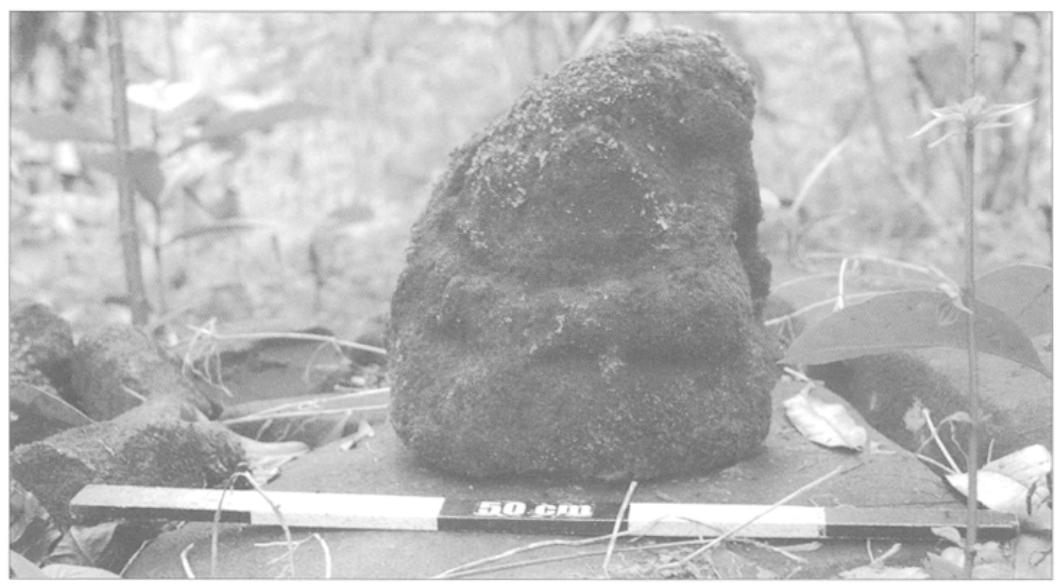

Figure 6 : Batur, petit Gaṇeśa découvert à côté du yoni.

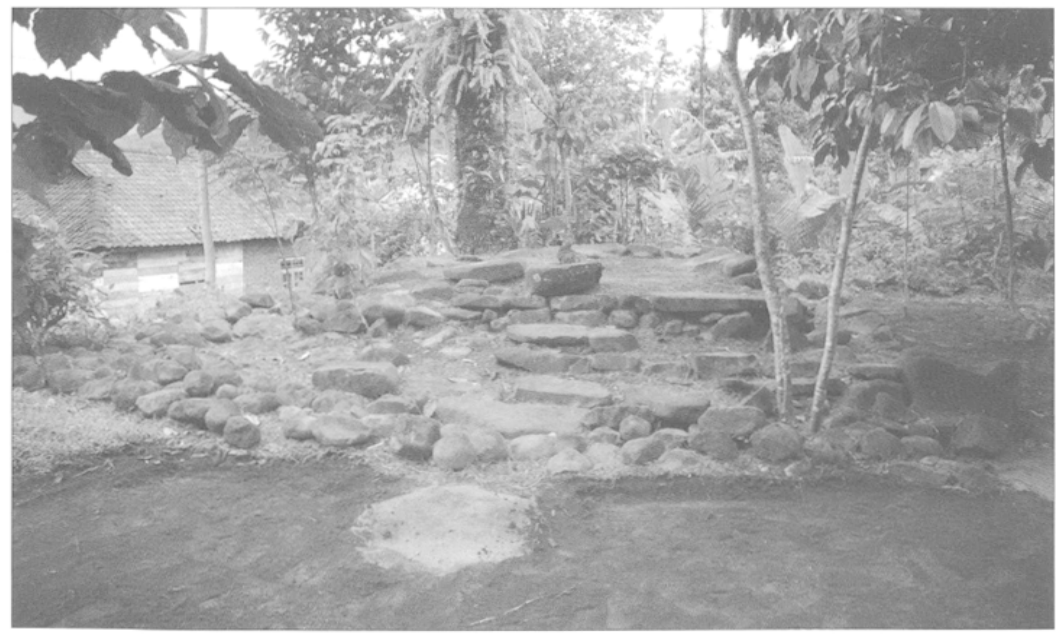

Figure 7 : Punden Wali Ajar Pendek, vue de la terrasse supérieure. 


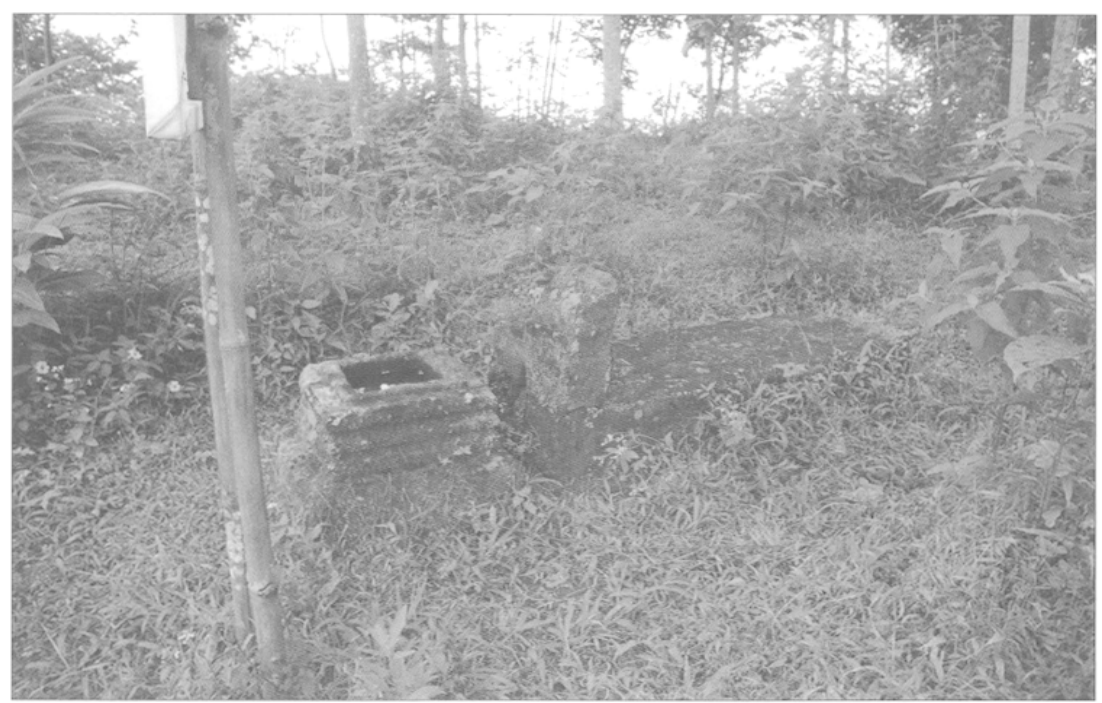

Figure 8 : Cepit, yoni et pierre de taille encore in situ.

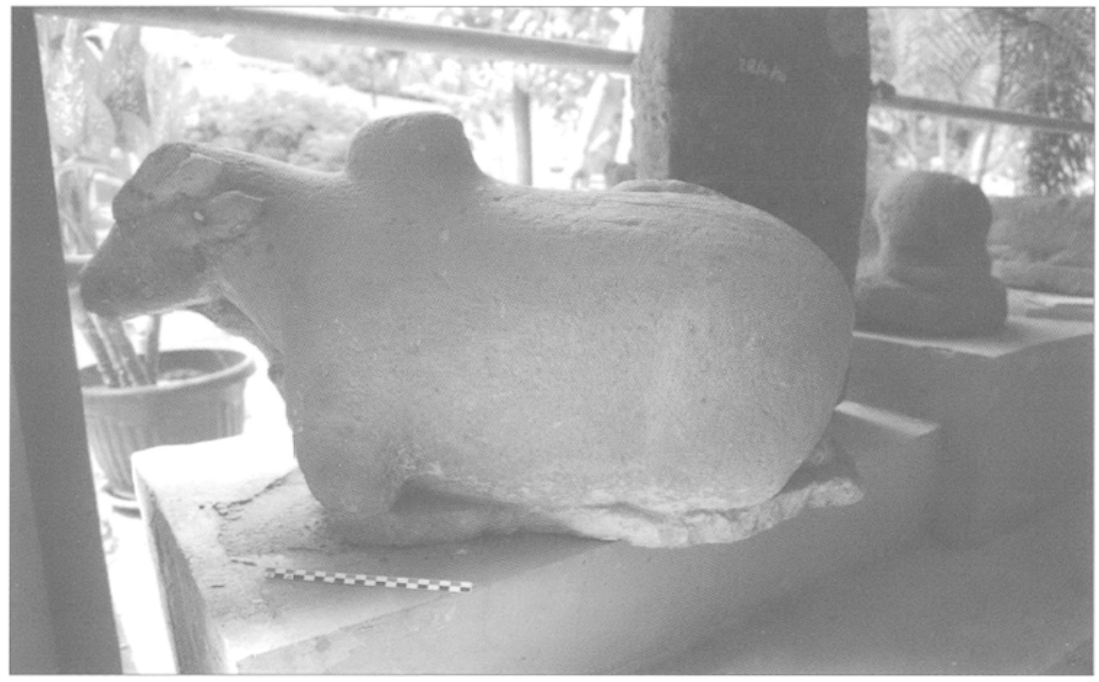

Figure 9 : Taureau provenant de Cepit (musée Ronggowarsito 04.00042).

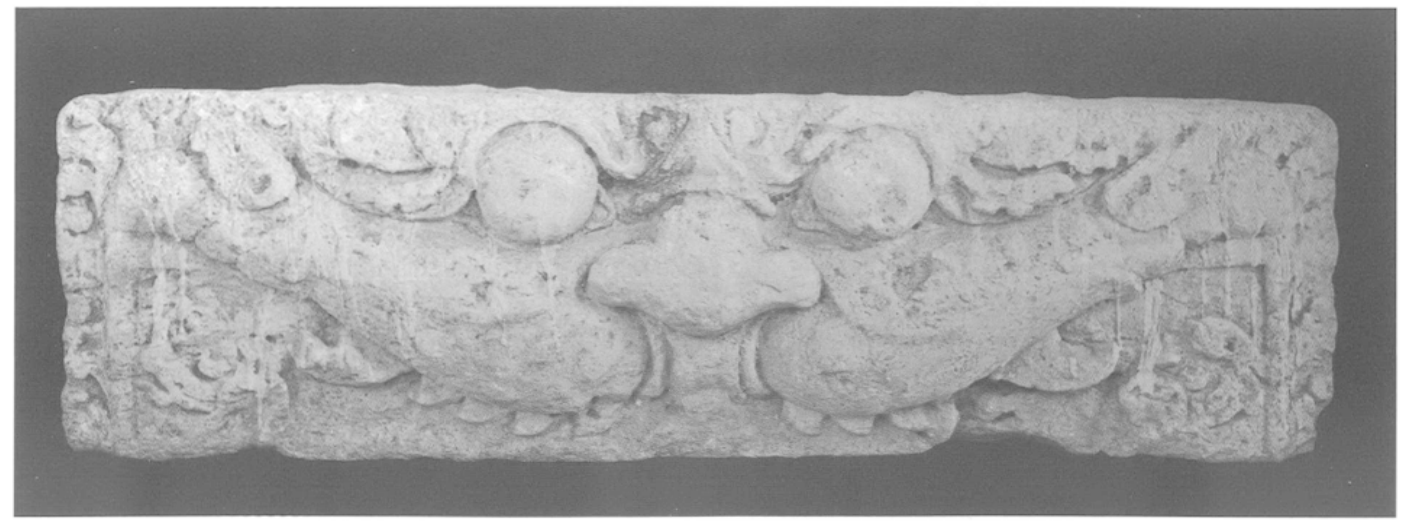

Figure 10: Linteau avec tête de $k a \bar{l} l a$ provenant de Cepit (service du tourisme et de la culture, district de Batang). 


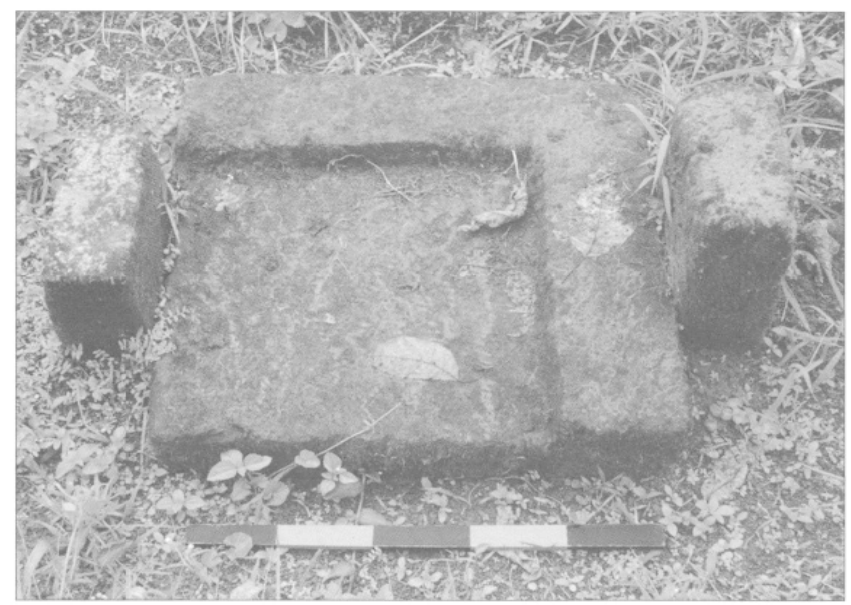

Figure 11 : Kepyar, fragment d'édicule d'angle.

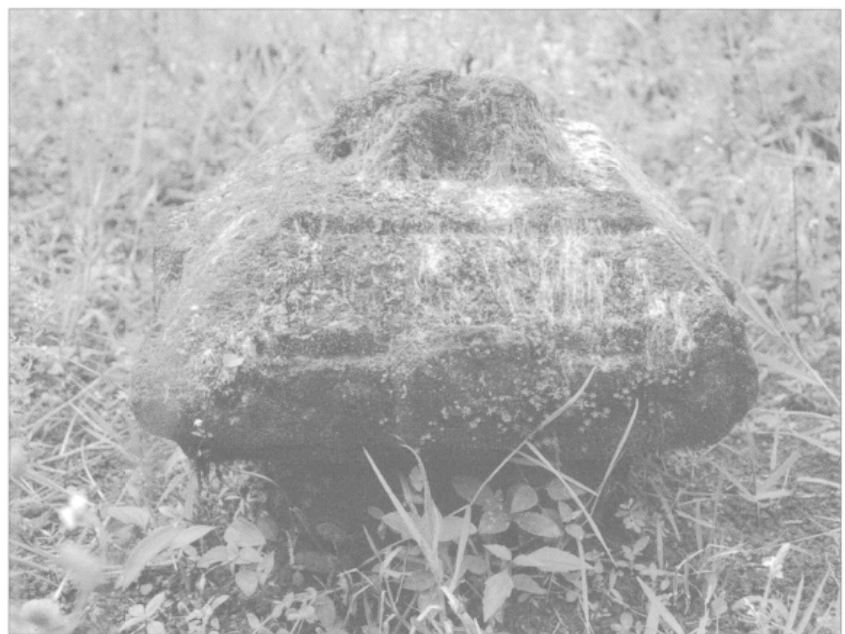

Figure 12: Kepyar, pierre de temple en réemploi dans une tombe musulmane moderne.

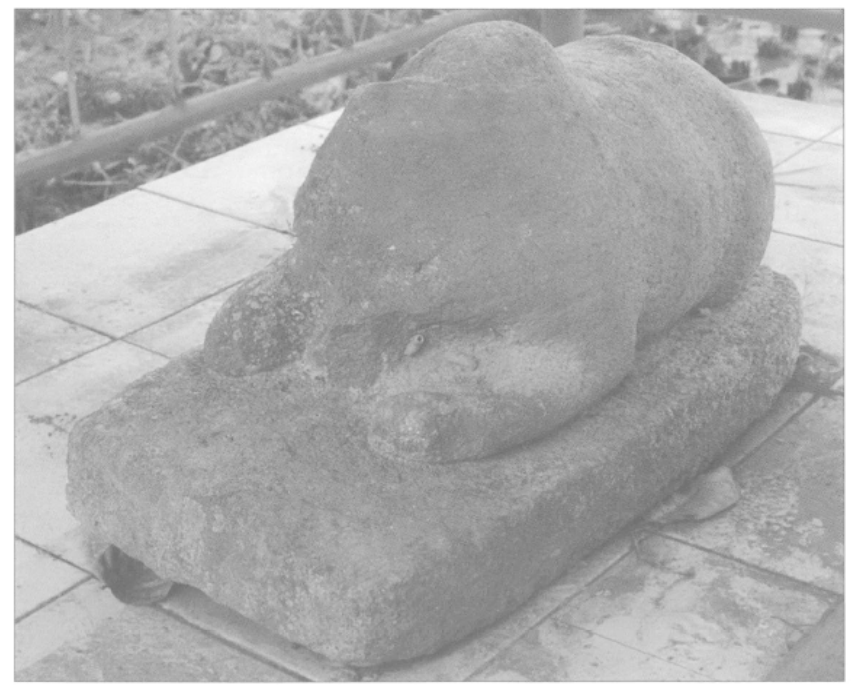

Figure 13 : Klenteng, statue de taureau. 
Figure 14 : Fragment de linteau provenant de Deles (musée Ronggowarsito, 04.00028).

Figure 15: Durgā provenant de Klenteng (musée Ronggowarsito, 04.00263).
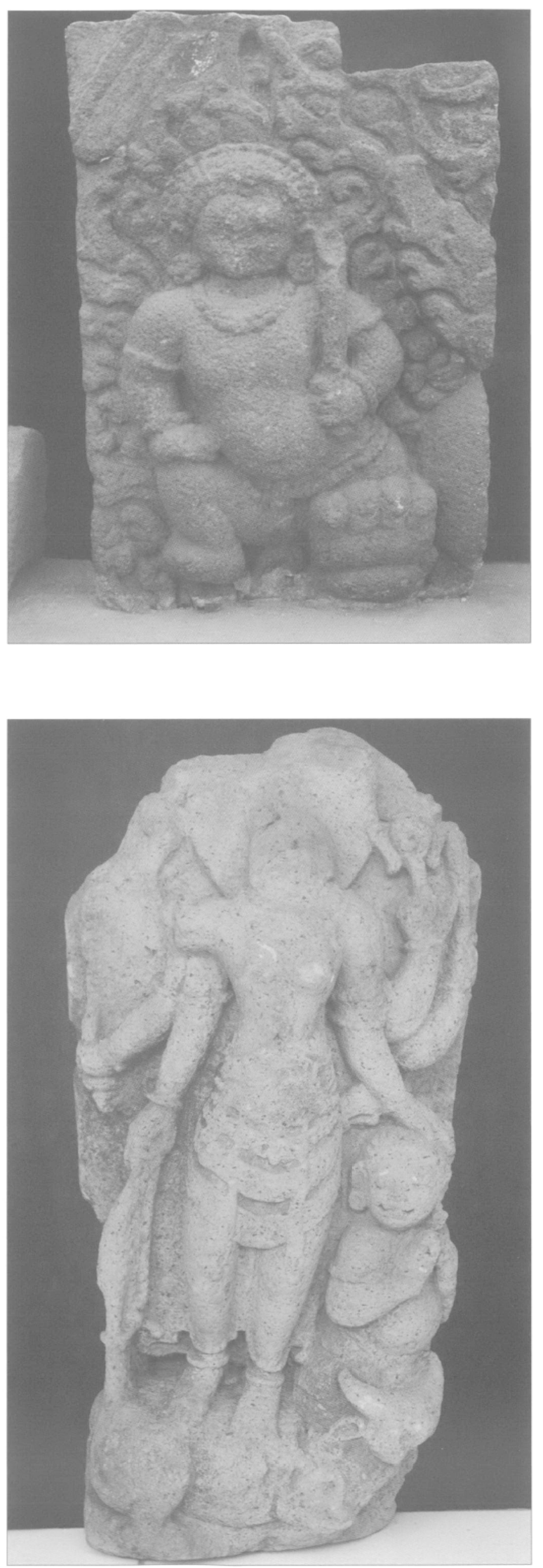


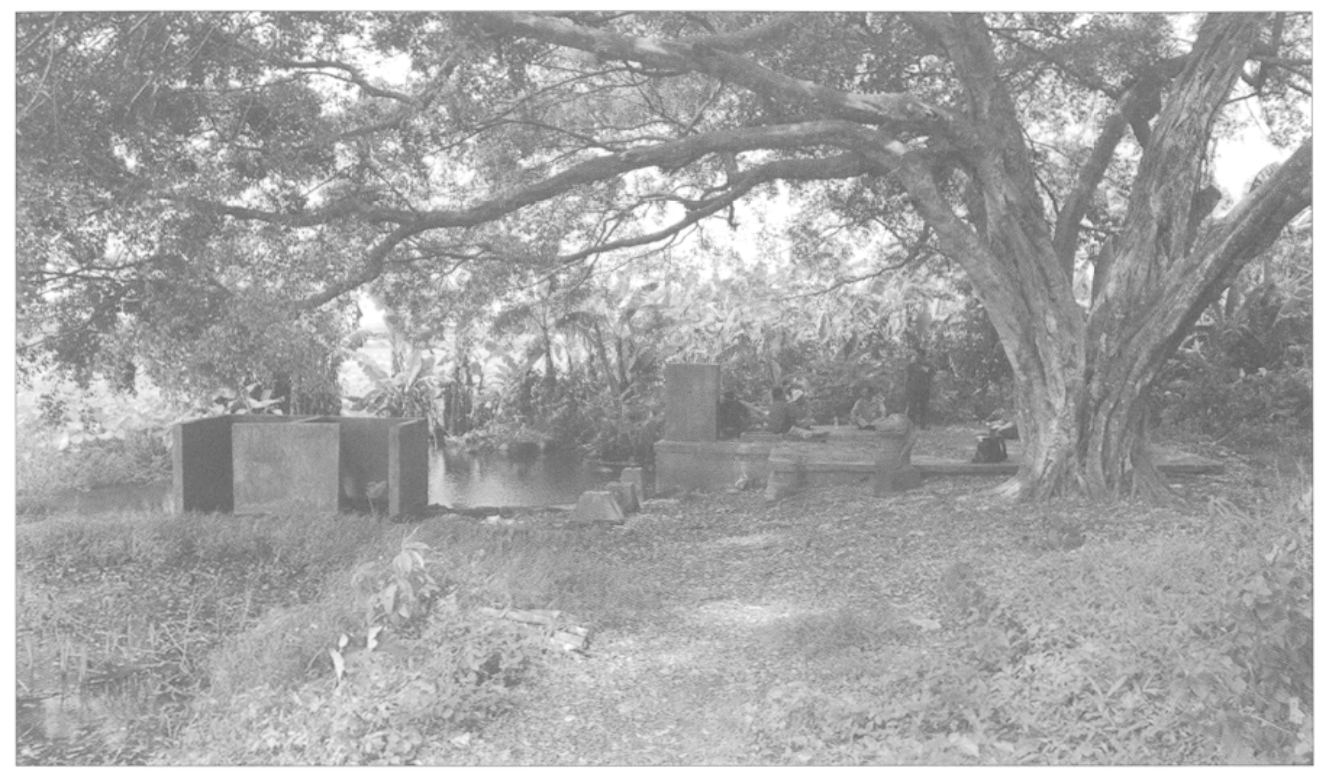

Figure 16: Balekambang, constructions modernes près de la source.

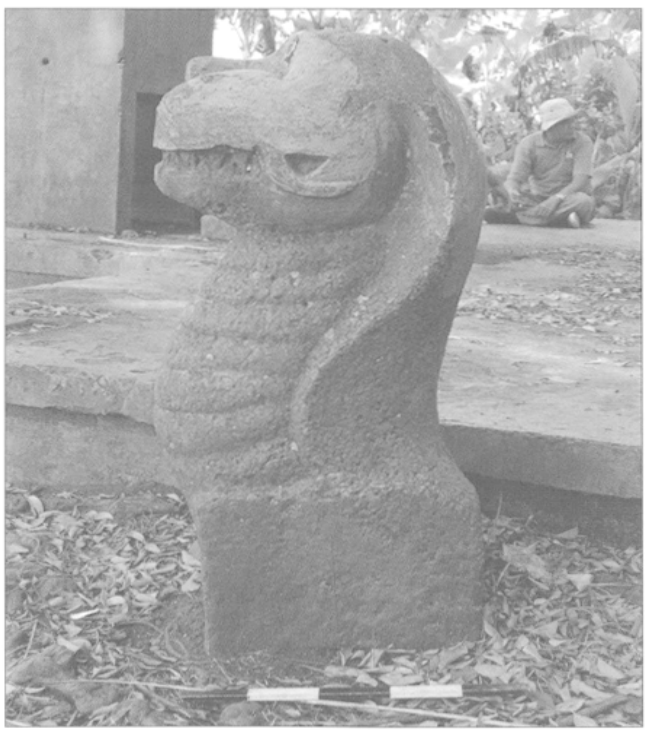

Figure 17 : Balekambang, nāga ancien remodelé avec du ciment.

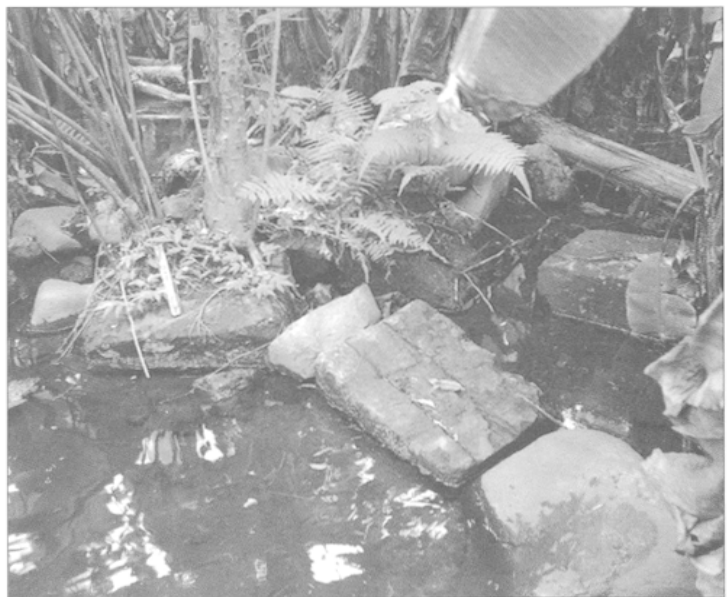

Figure 18 : Balekambang, pierre de taille. 


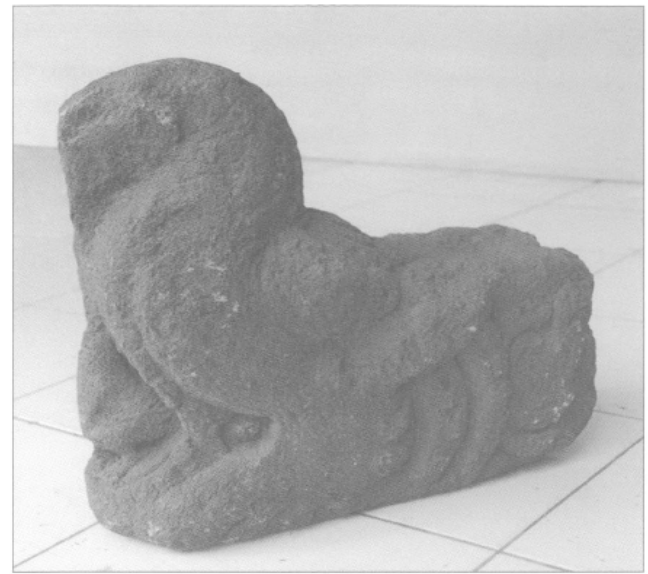

Figure 19: Makara provenant de Balekambang (musée Ronggowarsito, 04.00266).

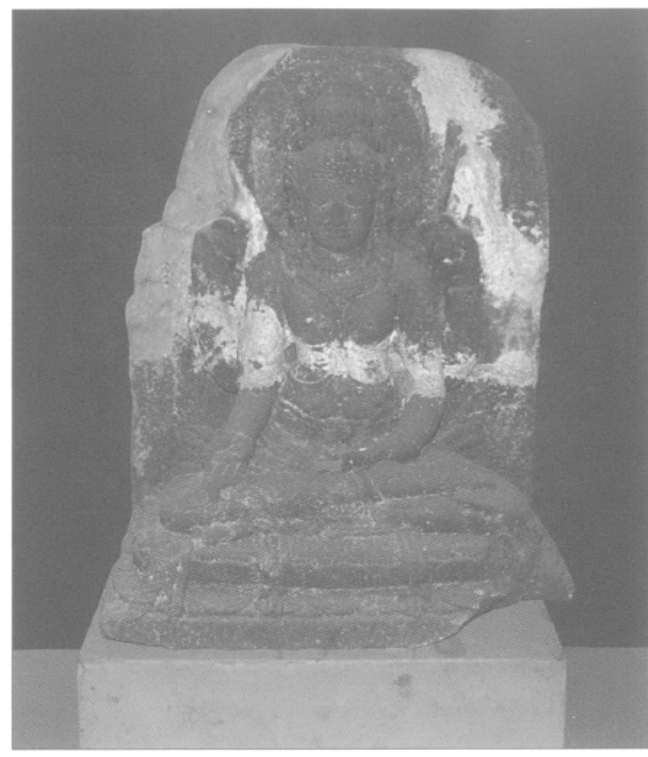

Figure 20 : Statue de Śrī provenant de Balekambang (musée Ronggowarsito, 04.00492).

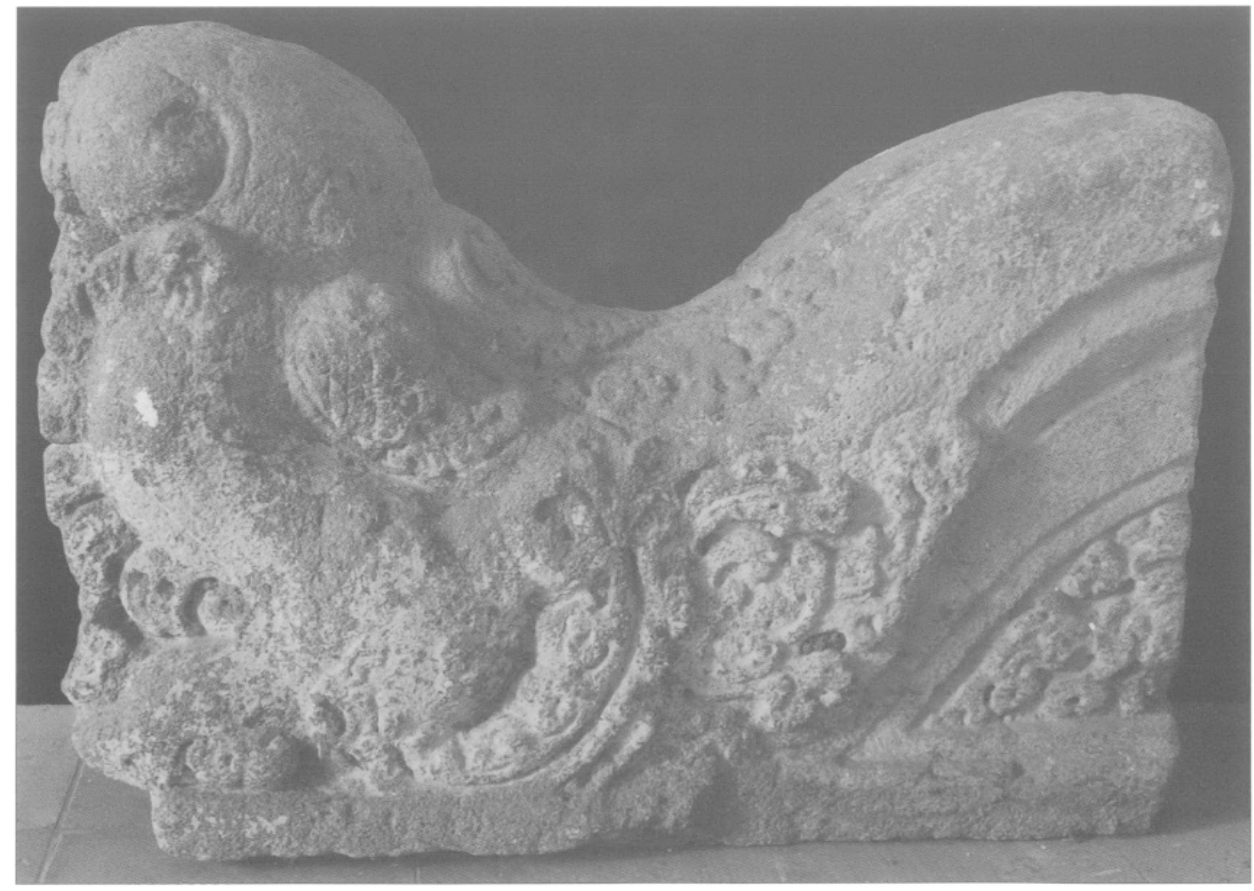

Figure 21 : Makara provenant de Balekambang (musée Ronggowarsito, 04.00079). 


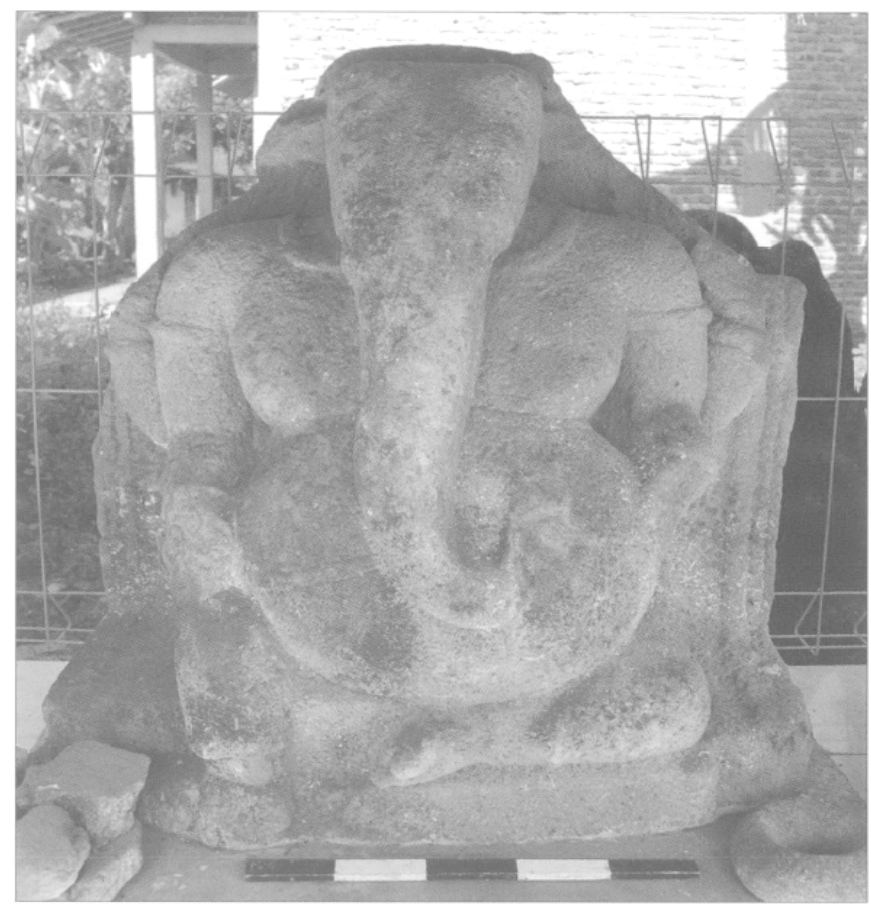

Figure 22 : Pejaten, Gaṇeśa.

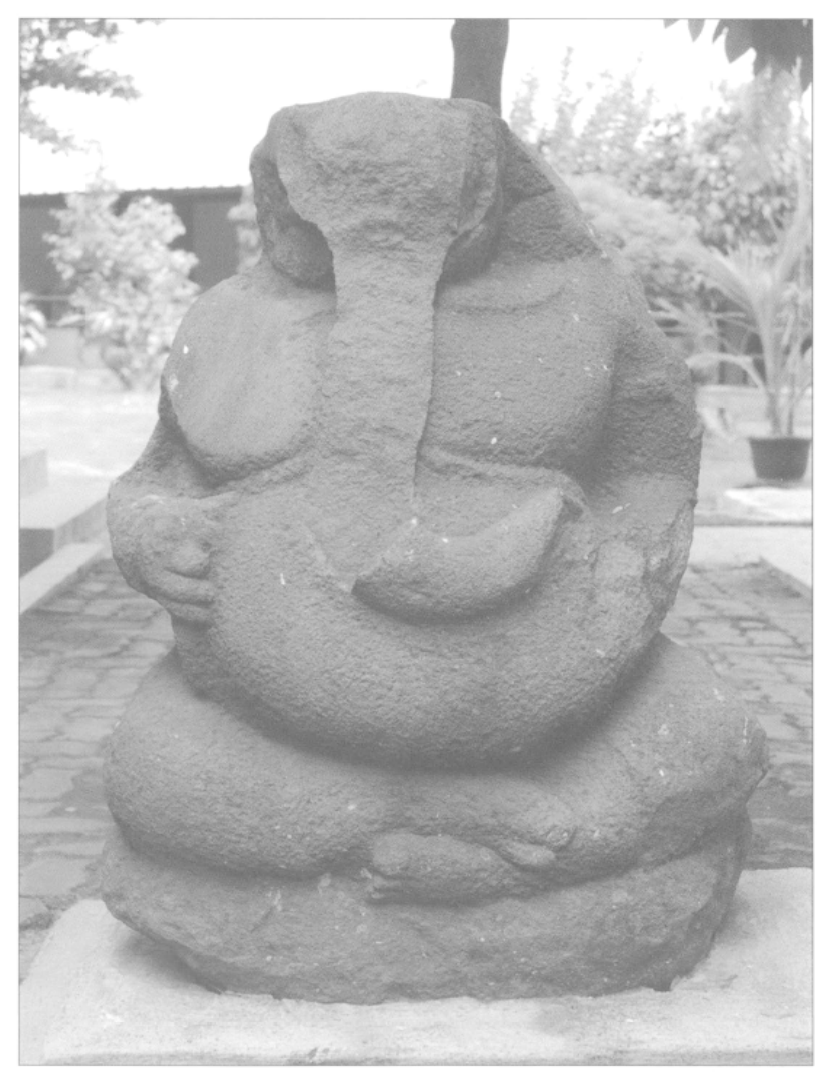

Figure 23 : Ganeśa provenant probablement de Pejaten (musée Ronggowarsito, 04.00089). 


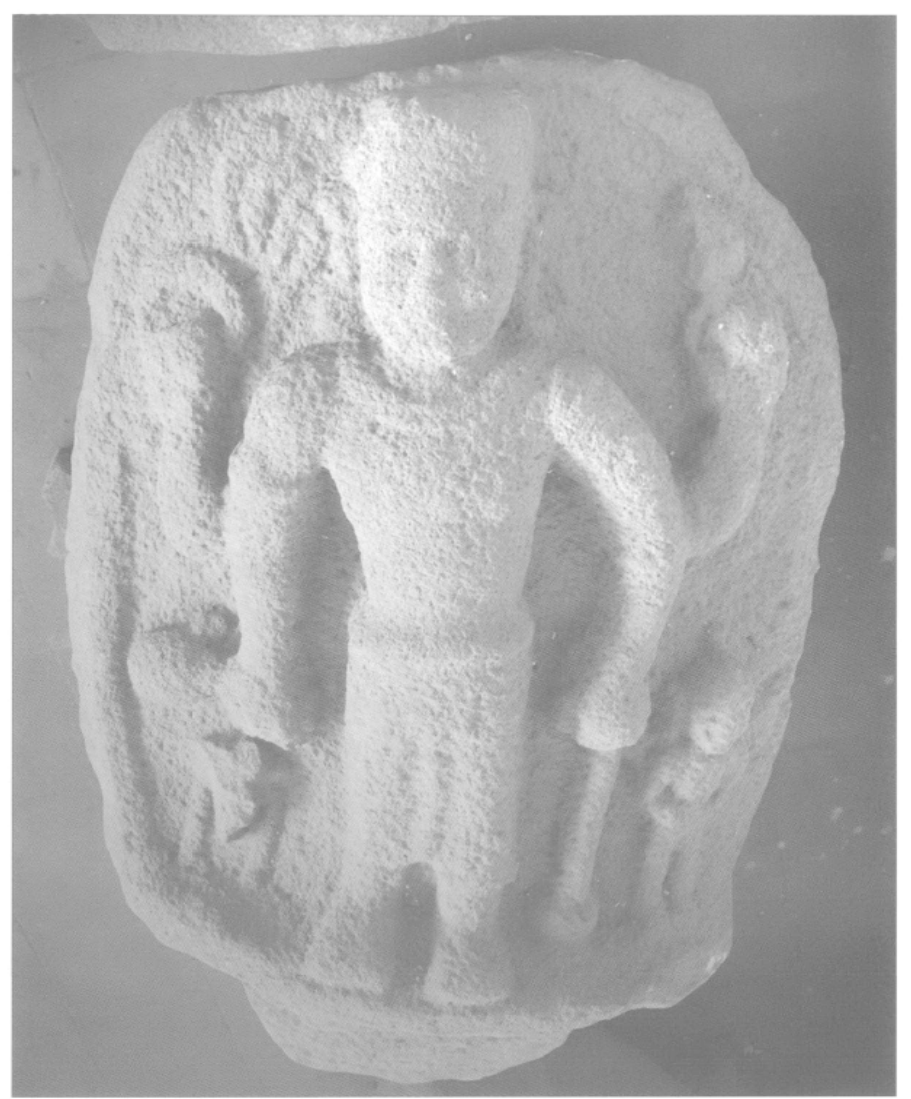

Figure 24 : Statue de Vișṇu ou de Hari-Hara provenant de Pejaten (musée Ronggowarsito. 04.00067).

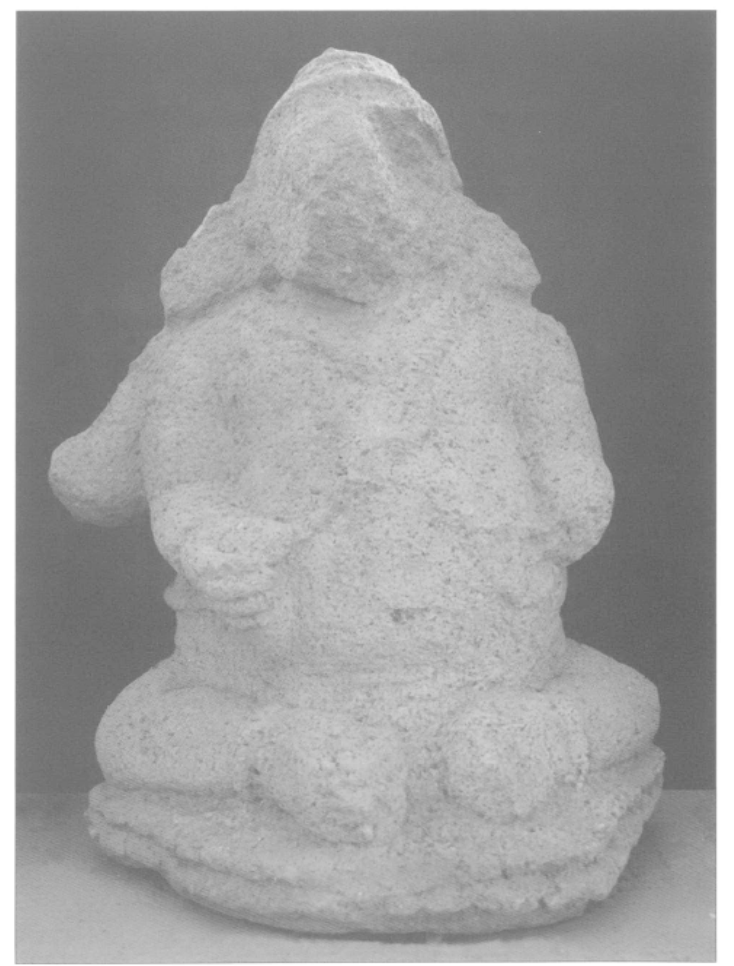

Figure 25 : Ganeśa provenant de Pejaten (musée Ronggowarsito. 04.00013). 